\title{
Job quality in the crisis - an update of the Job Quality Index (JQI)
}

Janine Leschke, Andrew Watt and Mairéad Finn

Working Paper 2012.07 


\title{
Job quality in the crisis - an update of the Job Quality Index (JQI)
}

\author{
Janine Leschke, Andrew Watt and Mairéad Finn
}

Working Paper 2012.07

european trade union institute 
Brussels, 2012

- Publisher: ETUI aisbl, Brussels

All rights reserved

Print: ETUI Printshop, Brussels

D/2012/10.574/31

ISSN 1994-4446 (print version)

ISSN 1994-4454 (pdf version)

The ETUI is financially supported by the European Union. The European Union is not responsible for any use made of the information contained in this publication. 


\section{Contents}

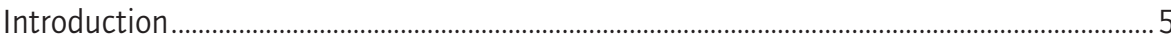

1. Constructing the job quality index: data and methods ....................................................

2. Discussion of sub-indices and overall job quality: 2010 results .................................... 8

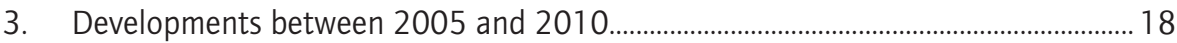

4. Detailed analysis of the sub-index 'working conditions and job security' ................25

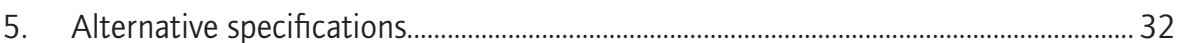

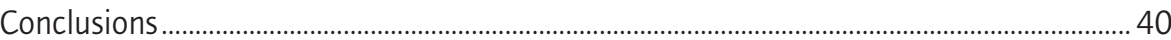

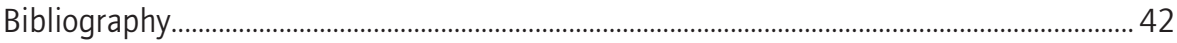

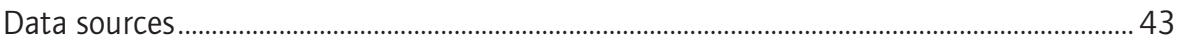

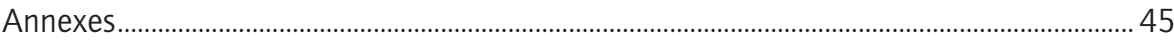

ETUI Working Papers .............................................................................................................. 50 



\section{Introduction}

The Lisbon Strategy, launched in 2000, called for the creation of 'more and better jobs' in Europe. The quantitative employment rate targets were used regularly to benchmark countries as part of the European Employment Strategy (EES). This was not the case, however, with the quality of employment indicators which were adopted at the Laeken Summit in December 2001 and subsequently coined "Laeken indicators" The quality of employment concept and the Laeken indicators are currently under revision to make them more applicable and take account of the criticism they have received (see e.g. Davoine et al. 2008; PeñaCasas 2009; Bothfeld and Leschke 2012). ${ }^{1}$

Until the onset of economic crisis some progress had been achieved in bringing more Europeans into paid employment and in cutting unemployment rates. The situation in regard to betterjobs' isless clear. On theonehand, thereisawidespread perception that many of the new jobs created are bad jobs': workers are being asked to work longer and/ or more 'unsocial' hours, and to accept non-standard employment contracts. At the same time, work intensity is widely perceived to be on the rise. Meanwhile, the increasing role of services in the economy and the move to a knowledge-based society is considered by many to hold out the promise of higher job quality, particularly as regards physical work factors.

Against this background, we have created a synthetic job quality index (JQI) for the EU27 countries in an attempt to shed light on the question of how European countries compare with each other and how they are developing over time in terms of job quality (compare Leschke, Watt and Finn 2008; Leschke and Watt 2008, Leschke et al. 2011). The job quality index is compiled on the basis of six sub-indices: wages, non-standard forms of employment (inverted), working time and work-life balance, working conditions and job security, access to training and career development, and collective interest representation. These sub-indices reflect the multifaceted concept of job quality (e.g. Muñoz de Bustillo 2012; Dahl et al. 2009; Green 2006) and allow benchmarking of countries with regard to different aspects of job quality.

The period between the last analysis of the J QI, which was based on data from 2005/6, and this most recent analysis (data from 2010) has been notable for having experienced the worst economic crisis since the Great Depression, acrisis that in Europe is, at the time of writing, far from over. In addition to the impact of ongoing longer-term structural trends (such as tertiarisation, feminisation), we would expect our results to have been influenced by the economic crisis and its knock-on effects on industrial structures and labour markets. An obvious question is whether the depth and duration of the crisis in different countries are linked in systematic ways to indicators of job quality. We expect, though,

1. The Laeken indicators go well beyond the issue of job quality in that they include, for example, information on employment, education and child-care, while at the same time, since they were inevitably the result of compromise, they disregard important dimensions of job quality such as wages. Furthermore, they are not assembled into a single index that would allow EU countries to be benchmarked in terms of job quality. 
that the impacts will be differentiated. In particular, one could hypothesise that opposing impacts can lead to mixed outcomes: on the one hand, the rise in unemployment and the declining bargaining power of labour brought on by the crisis might be expected to have a deleterious effect on the quality of existing jobs. On the other hand, there may be compositional effects, specifically the more than proportional destruction of poor-quality jobs, that actually push up average national job quality as measured by the JQI. We examine these issues in section 3 of this paper.

In order to structure the presentation of the data, we make frequent reference to clusters of countries based loosely on the classification developed in the wake of the seminal work by Gøsta Esping-Andersen (1990) and refinements of this approach (Ferrera 1996; Esping-Andersen 1999). We distinguish between the Nordic (or social democratic) countries (Denmark, Finland, Sweden), the Anglo-Saxon (or liberal market) countries (UK and Ireland), the Continental (or Conservative/ corporatist) countries (Austria, Belgium, France, Germany, Netherlands, Luxembourg), the southern European (or Mediterranean) countries (Greece, Portugal, Spain, Italy) ${ }^{2}$, and the central and eastern European countries (Bulgaria, Czech Rep., Estonia, Hungary, Latvia, Lithuania, Poland, Romania, Slovakia, Slovenia). The two Mediterranean islands - Malta and Cyprus - can be grouped with the central and eastern European countries as part of a "New Member State" group, although it would seem more logical to group them with the southern countries. For a fuller discussion in the context of job quality, the reader is referred to Leschke and Watt 2008 (28ff.) where analysis showed a considerable relevance of such clusters, particularly for the Nordic and Anglo-Saxon countries, to some degree for the Continental group, and rather less so for the southern countries, alongside quite considerable divergence within the NMS group.

Our interest in devising a quantitative index of job quality for all EU27 countries that can be regularly updated and is comparable over time and across gender necessitated some compromises in terms of thematic coverage and depth. In some areas this entails the need for cautious interpretation of the results. The JQI is not a substitute for more in-depth studies of particular sub-fields (e.g. Gallie 2007; Drobnic and Guillen 2012) or countries (e.g. Berckmans et al. 2011; Hofinger et al. 2009; Fuchs 2009). It is intended to complement these studies by providing a monitoring tool for cross-country and over-time comparisons across the whole European Union, disaggregated by gender.

This paper proceeds as follows. The next section briefly highlights the methods used to construct the J QI and make it comparable over time. Section 2 presents the results for 2010 for the sub-indices and the overall job quality index, for the purpose of contextualising the following three sections. Section 3 analyses how the countries evolved overall and in terms of the different sub-fields of job quality between 2005 and 2010 also in light of the crisis. Section 4 analyses,

2. Italy is sometimes seen as split between the southern and the continental group. Esping-Andersen (1990) did not specify a distinct southern regime and placed Italy within the continental group. 
in more detail and for a contrasting set of countries, developments in the working conditions and job security sub-index. Section 5 considers alternative specifications for various sub-indices and tests these for the impact of changes in the indicators used on the outcomes. Section 6 concludes.

\section{Constructing the job quality index: data and methods}

The six sub-indices of the JQI are chosen to reflect the issues that affect workers' perception of whether or not they hold a 'good job'. Issues relating to the social insurance and welfare systems, and also quantitative indicators of labour market performance (such as employment rates) were not included. This reflects a deliberate choice to focus the JQI on the employment relationship itself (in contrast to the Laeken indicators, for example). On the other hand, data limitations inevitably curtailed the choice of sub-indices and theindicators therein, even though their inclusion would have been desirable.

Each of these six sub-dimensions is composed of at least two and a maximum of four indicators (some of which are themselves composites). As there is no single data source that captures all dimensions of job quality, the variables come from a range of data sources, most importantly the European Labour Force Survey (LFS) and the European Working Conditions Survey (EWCS). An overview of the sub-indices and their indicators, as well as the weightings used, is provided in Annex 1. For more details see the discussion in Leschke, Watt and Finn 2008:9ff. Alternative specifications for some indices are discussed in section 5 below.

The approach to constructing the European J QI, based on the six sub-indices, each composed of individual indicators, enables us to take an encompassing view of this multi-dimensional phenomenon. At the same time, however, this approach gives rise to a number of methodological issues in arriving at an overall J QI.

First of all, in order to permit composition, the data for each indicator have to be normalised. This is done by setting a maximum value (at the value of the best performer) and a minimum value (at the value of the worst performer) for each indicator. On this basis a value can be assigned to each country in the range between zero and one for each indicator. ${ }^{3}$ Higher values represent relatively higher levels of job quality for the indicator in question. In order to be able to compare the results for men and women, the maxima and minima 'total' figures for the relevant variable are used to normalise the male and female data. For the comparison over time 2005 is chosen as the baseyear. This is done separately for the total, male and female figures, i.e. unlike in the cross-sectional comparison, for the comparison over time the maxima and minima for each population group in 2005 is used to normalise the data for that group for 2010.

3. Expressed mathematically the formula for indicator $i$ and country a is: (value $\left.{ }_{\mathrm{ia}}-\min _{\mathrm{i}}\right) /\left(\max _{1}-\min _{\mathrm{i}}\right)$. 
To address the issue of weighting the following 'mixed' approach has been adopted. No attempt is made to weight the six different sub-indices of the J QI. A country's JQI is the sum of its scores on these sub-indices divided by six (the number of sub-indices). Implicitly then the sub-indices are accorded equal value. In fact we emphasise the findings for the six sub-indices, (see the discussion in Leschke, Watt and Finn 2008:9ff.) rather than the overall J QI, not least because results differ, in some cases appreciably, between the indices as well as between men and women. Meanwhile, the contributions of the two, three or four different indicators to each sub-index are weighted. For instance, the two components of the first sub-index ('real wages' and 'in-work poverty') are weighted 0.7 and 0.3 respectively. This introduces an element of subjectivity, but one that appears manageable because it relates to the relative importance of a limited number of indicators contributing to one particular aspect of job quality (and thus likely to be rather similar in nature). ${ }^{4}$

\section{Discussion of sub-indices and overall job quality: 2010 results}

This section discusses how the EU27 countries in 2010 perform on the different sub-indices and with regard to overall job quality as expressed by the unweighted average of the normalised scores on the sub-indices.

While we are aware that the reader may find this section in places somewhat tiresome, it is important to decompose overall job quality and discuss the results accordingly, as similar overall levels in job quality between countries but also between men and women - can derive from very different profiles with regard to the various job quality dimensions. Figure 1, which shows gendered results for the EU27, nicely illustrates this. Overall job quality (Final J QI) hardly differs between men and women. When we look, however, at the different subdimensions of job quality, we see substantial gender differences. It is a wellknown fact that men, on average, earn higher hourly wages than women (gender pay gap). They also have better outcomes with regard to employment form (less likely to be involuntary part-time or temporary employed) and they do somewhat better in terms of skills and career development. Women, according to our index, have better outcomes in terms of working conditions and job security - this is due, among other things, to sectoral segregation. And they do substantially better on the working time and work-life balance sub-index, not least due the fact that they are often in the position of having to choose jobs that allow them to combine work and family life. Unfortunately, we lack gendered figures on collective interest representation.

4. The sensitivity of the overall results to changes in these subjective weights has been checked for four sub-indices (wages, non-standard employment, skills and career development and collective interest representation), where weighting changes might have been expected to influence the results. It emerges that plausible moderate shifts in these weightings do not lead to fundamentally different rankings for the sub-indices in question (for more information refer to Leschke, Watt and Finn 2008). 
Figure 1 Comparison of sub-indices and JQI for EU27 by gender, 2010

$\square$ men $\quad \square$ women $\quad$-total

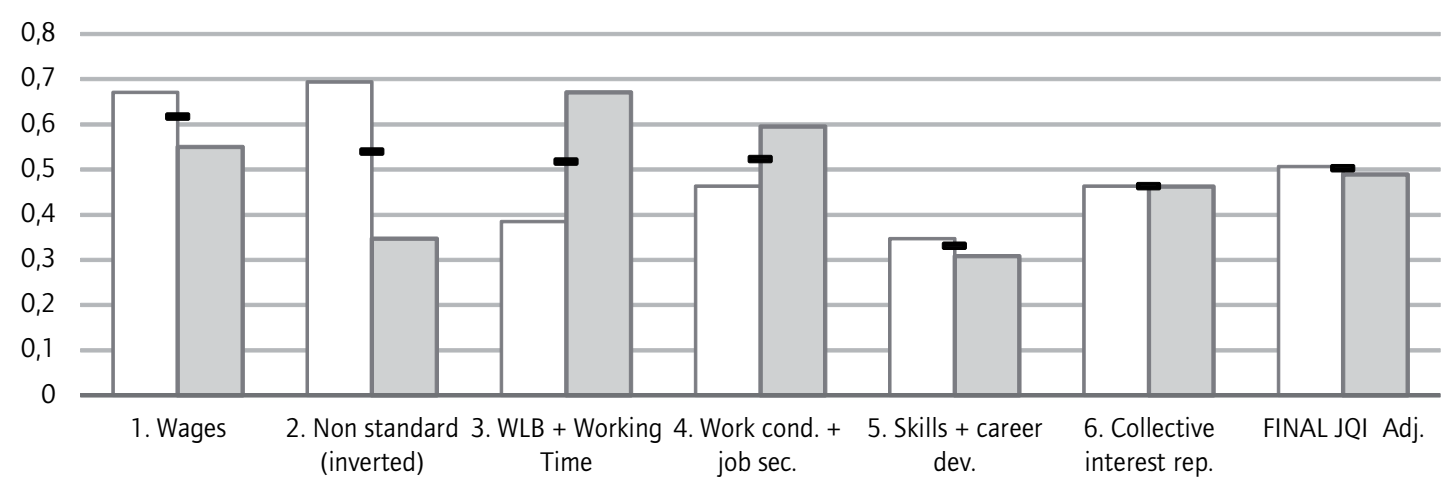

Source: own calculations.

Note: No gendered figures available on collective interest representation.

The need to earn a wage is an important, albeit not the only, reason why workers perform paid labour. As explained in more detail in Leschke, Watt and Finn (2008), the wages sub-index consists of average wage levels per employee, expressed in purchasing power standard to allow for differences in price levels between countries ${ }^{5}$, plus a distributional component, the share of the working poor; this is a relative, not absolute, measure. The (hourly) gender pay gap is used to calculate the wage levels by gender. ${ }^{6}$

Figure 2 Sub-index on wages, 2010

$\square$ men $\quad$ women $\quad$-total

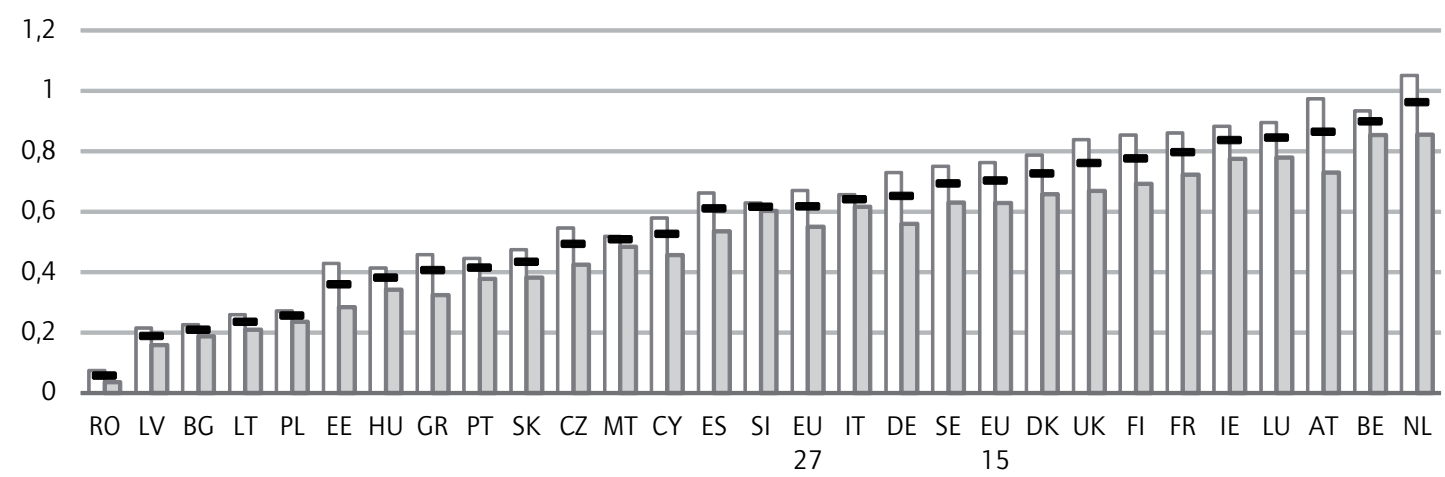

Source: own calculations

As can be seen from Figure 2, the countries are spread evenly across the distribution. Unsurprisingly, the bottom seven countries are CEE new member states.

5. See section 5 for a discussion of alternative specifications.

6. The working poor measure is available by gender; however, due to the fact that this measure is based on a household concept, for this analysis we use the national totals only. 
Romania performs worst, by a considerable margin, having the second-lowest wages and the largest share of working poor. The lower middle and middle of the distribution consists of a mixture of southern and eastern European countries. The upper middle and top consists only of countries from the Continental, Anglo-Saxon and Nordic groups, but there is no obvious pattern among them, except that the top countries are all 'Continental'; this may, as noted in earlier work, partially reflect the fact that the wage measure used includes social insurance contributions and is therefore sensitive to differences in the way that social insurance systems are financed, with reference to the Nordic countries, for example.

Unsurprisingly too, a gender gap emerges from our wages indicator - which accounts for gender differences in working hours - in favour of men in all countries, although the gap is very small in three CEE countries (Bulgaria, Poland and Slovenia) and also in Malta and Italy. In some cases the hourly gender wage-gap is quite substantial: in Austria, the Czech Republic, Estonia, Finland, Germany and Slovakia it exceeds 20\%, and in the Netherlands, the best overall performer in this sub-index, it is only slightly below that figure.

Where the gender differences are large they have significant implications for cross-country rankings. For example, men in Estonia have the same wage score as women in Cyprus, which is seven rungs higher on the overall ranking. Similarly, British men have a higher score than women from any country. Conversely, German women achieve a score roughly equal to that of Czech men, whereas in the overall rankings Germany is six places ahead.

Non-standard employment has been a main driver of employment creation over the 2000s and it has been criticised on different counts: often it does not function as a stepping stone to regular employment and it carries additional disadvantages too, including less access to social benefits and in-work training and less likelihood of collective interest representation.

This sub-index is made up of the share in total employment of part-time workers who report that they could not find a full-time job and the share of fixed-term workers who could not find a permanent job. (It is inverted to follow the logic of the other sub-indices). In other words, only forms of atypical employment that are clearly exercised involuntarily are considered as reflecting negatively on job quality.

The country spread is large, ranging between 0.1 and 0.9 with steep increases particularly at the lower end of the distribution and less variation at the upper end. Spain is the worst performer by far, while Bulgaria, together with Luxembourg and Slovakia, is doing best (Figure 3). This sub-index is notable in that the central and eastern European countries which, on most sub-indices, are under-performing are mostly found at the upper end - they usually have both low part-time and low fixed-term employment shares - with Poland, however, as a very notable exception since in 2010 it had the highest fixed-term employment rate in Europe. 
By contrast, the Nordic countries which perform very well on the majority of sub-indices, here perform rather poorly, and this is particularly true of Sweden. Southern European countries, with relatively high fixed-term employment shares and medium part-time shares but high rates of involuntariness on both, are found at the bottom of the distribution with slightly better outcomes for Greece. Corporatist countries with substantial shares of female part-time employment are found across the distribution, with particularly France doing poorly. The UK occupies a mid-position, while Ireland is among the worst performers due to its occupying the lowest position on the involuntary part-time indicator.

As shown in Figure 1, this sub-index clearly favours men, a fact predominantly attributable to the large gender differences in part-time employment. Country differences in this regard are large and are an outcome of values and norms that confer primary responsibility for careand household tasks on women, a situation which - in the absence of encompassing child and elderly care institutions will lead to women either not working at all or combining part-time work with care work. ${ }^{7}$ The eastern European countries which have no tradition of female part-time work show much higher gender equality on this sub-index than the Nordic, southern and most corporatist countries. The Netherlands represent an interesting case for they can be found in the upper-mid range here in spite of the fact that they have by far the highest part-time employment in the EU27 and also higher than average temporary employment, this being balanced out by the fact that very few people report working part-time involuntarily and the share of involuntary fixed-term is also among the lowest.

Figure 3 Sub-index on involuntary non-standard forms of employment (inverted), 2010

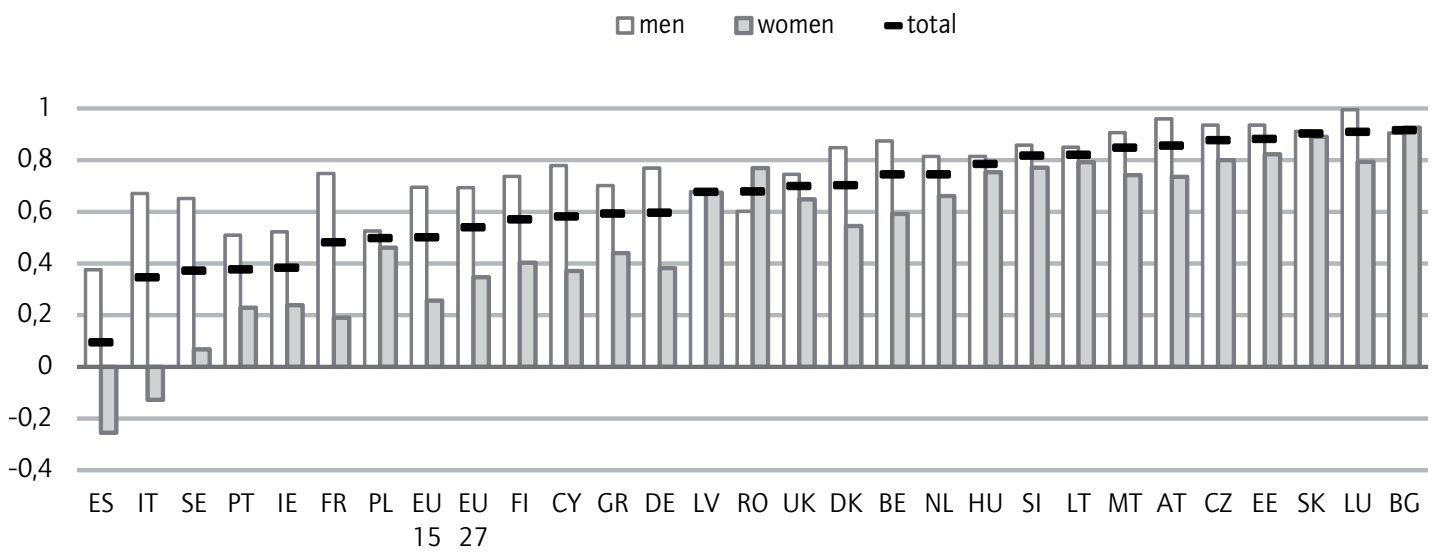

Source: own calculations

Note: In the cases of Spain and Italy the score calculated for women is negative.

This occurs when the gender gap is large in countries whose total values are rather low.

7. It is important to reiterate that we consider in this sub-index only those part-time workers who were unable to find a full-time job. We do not take account of part-time workers who are working part-time due to the fact that they are looking after children or incapacitated adults or because of other family and personal responsibilities. Adopting the latter option would have increased the gender differences even further. 
Working time is an important element in job quality. Excessive working hours and, generally, most forms of atypical work have been singled out as having particularly adverse impacts on job quality and workers' health. Work-life balance, depicting the degree to which paid employment is able to be combined with outside-work activities, including care work, is also commonly identified as an important component of job quality (Drobnic et al. 2011).

The working-time and work-life balance sub-index is composed of the share of employees working more than 48 hours a week and the average of the percentage of workers on shift work, week-end work, evening work and night work (both are inverted), as well as the share of part-time workers who did not want a full-time job and those workers who say that their working hours fit in well - or very well - with family/social commitments.

The spread of this index is large, with Greece ranking close to 0 and Denmark doing best with a ranking of 0.85 (Figure 4). Roughly half of the countries are bunched tightly at values between 0.5 and 0.6 whereas, particularly in the lower and upper end, the gaps between countries are substantial. The southern countries, with the exception of Portugal which has mid-range performance, perform particularly badly on this sub-index. They are known for having on average long working hours and at the same time relatively poor outcomes in terms of work-life balance. The central and eastern European countries also are below or only slightly above the EU27 average. Nordic countries - although less so Finland - are found at the top of the distribution; the UK and Ireland are also above average. The corporatist countries are spread across the distribution with the Netherlands, Belgium and Luxembourg doing particularly well and France doing particularly poorly.

As illustrated in Figure 1, women are on average doing considerably better than men on this sub-index. In fact, it represents in some regards the inverse of the sub-index on non-standard employment. Women indeed often choosejobs that allow them to combine work and family. The higher scores for women apply across the distribution and notably so in the UK and Germany. A number of countries - belonging to different welfare regimes and situated at the bottom or in the middle of the distribution - show relatively small gender differences. These are, in particular, Romania, Bulgaria, Portugal, Cyprus, Finland, Lithuania and Hungary. This greater gender equality in this sub-index cannot be put down to a single indicator but is attributable to country-specific reasons; it should be noted, however, that these countries all have comparatively low part-time employment shares for women.

As marginal working hours, usually defined as below 15 hours, have been put forward as a problematic feature of job quality, particularly in the discussions on precarious employment, section 5 will test an alternative specification of this sub-index. 
Figure 4 Sub-index on working time and work-life balance, 2010

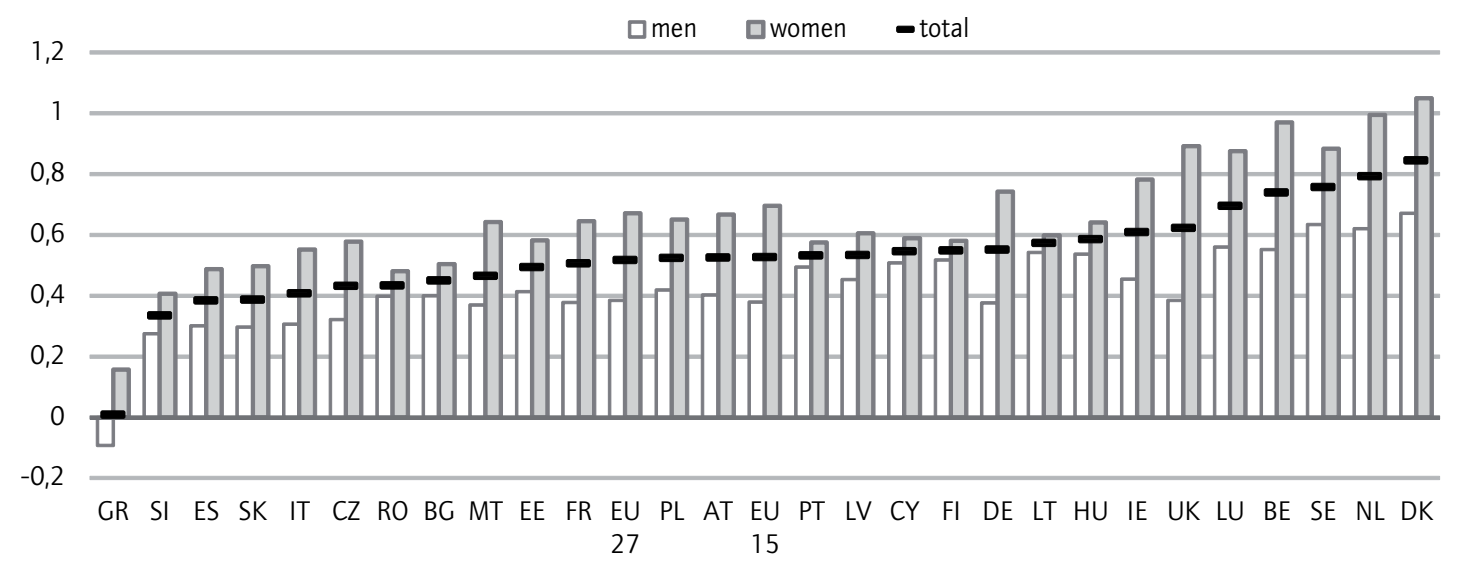

The working conditions and job security sub-index is a complex composite of a large number of individual indicators relating to work intensity, physical working conditions (noise, bodily strain, etc.) and autonomy at work, along with the subjective perception of likelihood of losing the job in the next six months. Indicators are inverted where appropriate. In section 4 below we go into considerably more detail on the individual components of this sub-index. Here only a brief overview is given. One consequence of the large number of indicators is immediately apparent from Figure 5: the spread between the countries is comparatively narrow, with most countries bunched between 0.3 and 0.7 . This suggests that the various indicators have a certain tendency to offset each other (absence of strong positive correlation between indicators).

The gender division within this sub-index is also extremely interesting. In the vast majority of countries women score substantially higher than men in this sub-index, reflecting factors such as the sectoral distribution of male and female employment. The generally higher scores for women reflect lower work intensity and physical stress factors, whereas male workers enjoy more autonomy than their female counterparts; there was no difference on average between the genders on fear of job loss. The exceptions to this rule are, interestingly, the three best-performing countries, Denmark, Netherlands and Finland (and in the other Nordic country, Sweden, there is virtually no gender difference although the country is rather further down the overall ranking). This is in spite of the strong sectoral division in the Nordic countries. Looking more closely at the sub-components, men and women in these four countries do rather similarly on physical stress and non-intensity of work (less so in Finland) whereas in all four countries men do better on work autonomy and women in Denmark and the Netherlands are less afraid of losing their job. 
Figure 5 Sub-index on working conditions and job security, 2010

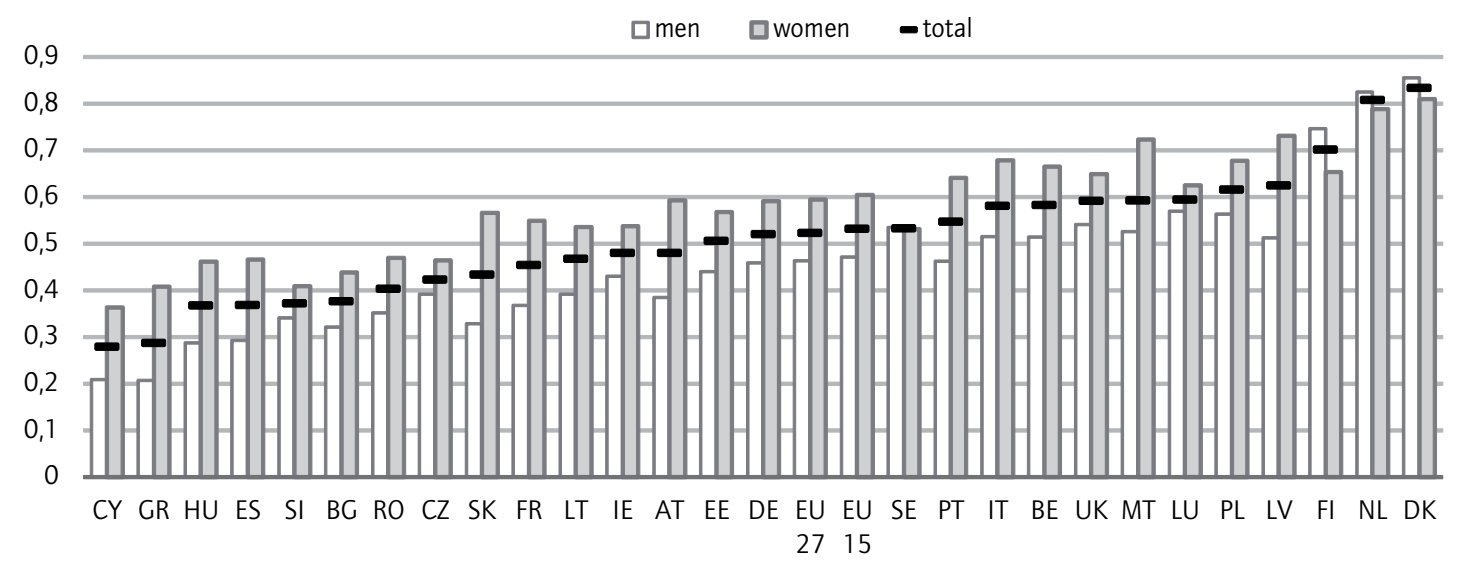

Source: own calculations.

Looking at the overall rankings, strong regional patterns are not obvious. The rankings of some CEE countries (especially Poland and Latvia) are higher than in other sub-indices. Latvia is the country in which work intensity is reported to be the lowest of all the 27 countries. But other 'welfare models' tend to be rather evenly spread across the distribution. This is not always true at the level of the four main groups of indicators, however. For instance, Britain and Ireland show similar performance in terms of work intensity (moderately poor) and physical stress (rather good), but there are considerable differences regarding work autonomy and fear of job loss. The Nordics all score well on work autonomy but are otherwise quite diverse measured against these yardsticks.

Skills and career development is an important aspect of job quality in that it helps workers to advance in their career and thereby avoid dead-end jobs. It is captured by the share of the adult population having participated in education/ training over the four weeks prior to the survey. ${ }^{8}$ This information is enriched by an indicator from the EWCS which records whether a person (strongly) agrees with the statement 'my job offers good prospects for career advancement'. It is problematic that this sub-index does not contain information on the type of training course and the intensity of the training (extent). This information is available only in specialised surveys such as the Continuing Vocational Training Survey (CVTS) which did not fulfil the requirement of our JQI that information be available in a timely manner and able to be updated over time.

Figure 6 illustrates that the spread, here again, is large with four of the central and eastern European countries (Romania, Lithuania, Slovakia and Hungary) displaying values below 0.1 and thus showing very poor results on this subindex, and Denmark, at the other end of the distribution, having a value of close to 0.9. The other central and eastern European countries all perform below EU average except for Slovenia. The southern countries are also found at the lower

8. The extent of skills development is not independent of the extent and formalisation of initial education which differs between European countries. We try to take account of this, to some extent at least, by restricting the training data to the adult population. 
end of the distribution with somewhat better results for Spain. Roughly half of the countries and all corporatist countries except for Luxembourg are found in the range 0.3 to 0.5 , thereby displaying close-to-average results. At the top of the distribution we see the Nordic countries, Luxembourg and the UK, with the UK and especially Denmark significantly outpacing the competition. ${ }^{9}$

Gender differences on this sub-index are not clear-cut. On the EU27 average women do somewhat better on education and training participation whereas men do considerably better on (the lower weighted) subjective assessment of prospects for career advancement. Looking at the country level, in the majority of countries men do better and this is particularly true in the lower performing countries. The inverse - women doing better than men - is true of the five countries - except Luxembourg - with by far the best performance (the Nordics and the UK).

Figure 6 Sub-index on skills and career development, 2010

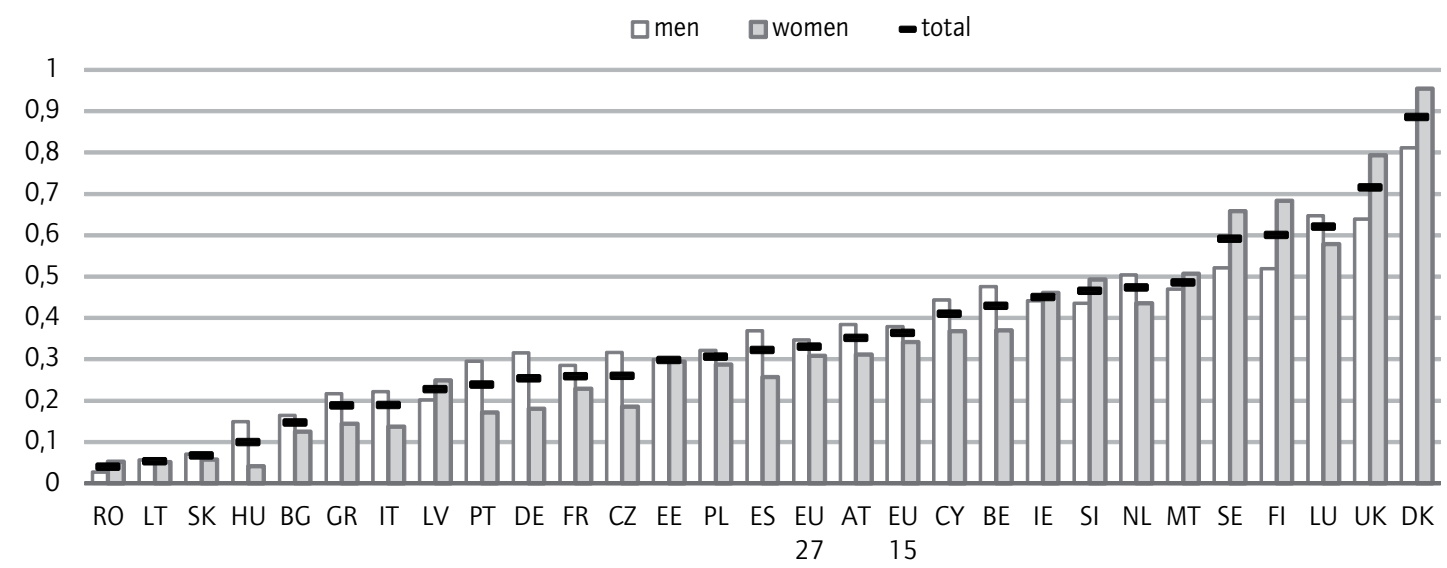

Source: own calculations.

Collective interest representation - a sense of voice by workers in their working environment - has been shown to be an important source of subjective job satisfaction, warranting its inclusion in such a composite index. However, data restrictions meant that the sub-index, when first calculated for the 2005 vintage of the J QI, was unsatisfactory in a number of regards (for details see the discussion in Leschke, Watt and Finn 2008). We are especially concerned that these data privilege systems that exhibit highly centralised bargaining and high rates of unionisation while failing to pick up 'functional equivalents', notably forms of workplace representation such as works councils which are important in certain countries such as Germany. One of these limitations is the lack of gendered data.

9. To some extent the UK ranking may reflect comparatively poor initial education and training systems which are then compensated for via more frequent training courses during working life; as noted, data restrictions mean that duration and quality of training are not covered. 
Figure 7 Sub-index on collective interest representation, 2010

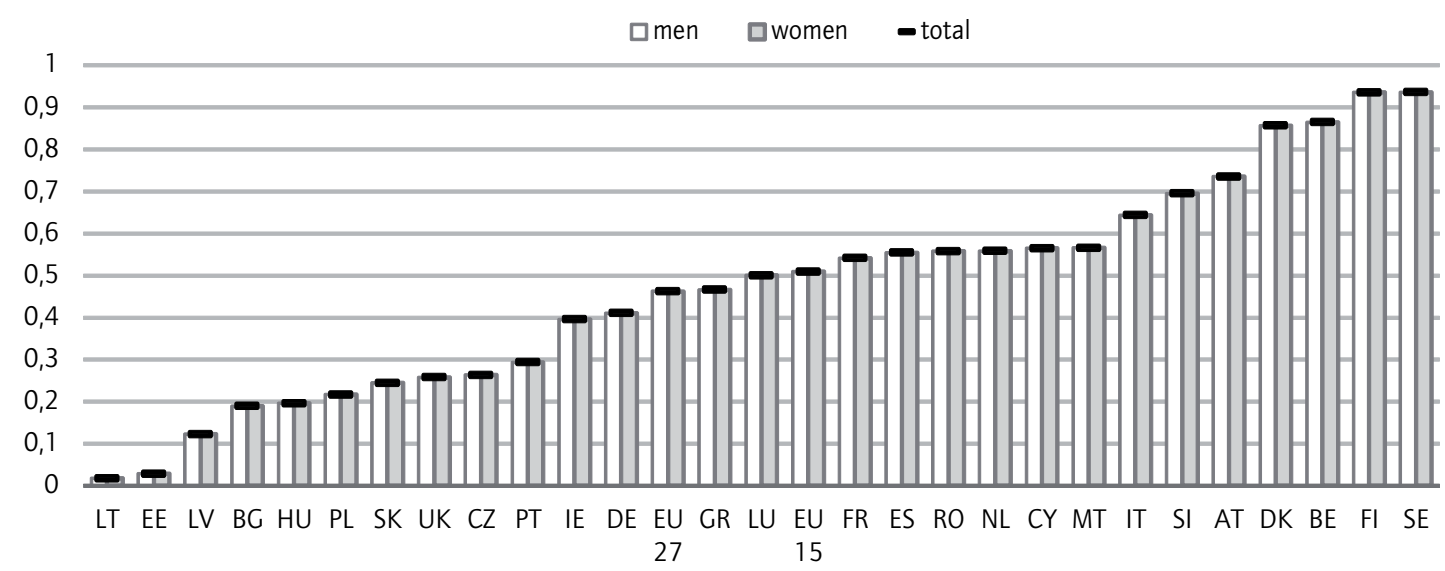

Weneverthelesspresentherethesub-indexusingessentiallythesamedataseries as in the 2005 exercise - trade union density and collective bargaining coverage - in order to enable comparison over time ${ }^{10}$. However, new comparative data has become available since 2005; this data will be briefly discussed in section 5 .

Countries are spread across almost the full 0-1 normalised range, suggestingthat high collective bargaining coverage and high rates of trade union density tend to go hand in hand, France being a well-known exception in this respect. Apart from a few exceptions, rather stark groupings of countries generally emerge, in line with thevarieties of welfare capitalism approach. Thethree Nordic countries areall in the top four, with Denmark only just outpaced by Belgium. ${ }^{11}$ The upper middle and centre of the distribution is dominated by continental but also many southern European countries; Slovenia is a well-known exception having similarities with Austria, but CEE member state Romania is also comfortably in the top half of the distribution. Generally, though, the CEE countries are concentrated in the lower third of the rankings, with the two English-speaking countries straddling the dividing line to the lower third of the distribution.

The overall job quality index (Figure 8) is an un-weighted average of the six sub-indices. Each of the six sub-indices therefore counts equally towards the total. ${ }^{12}$ In terms of country clusters, we find at the bottom of the distribution southern and central and eastern European member states, with the exception of Slovenia. Among the southern countries Italy is doingbest and indeed is more similar in terms of overall job quality - albeit due to different combinations of the sub-dimensions discussed above - to Germany, Cyprus and France, all of

10. Due to changes in the EWCS, the indicator of workers' involvement in decisions on work organisation had to be dropped, however.

11. These are all countries where the trade unions have an important responsibility in the payment of welfare benefits, and particularly the unemployment benefit system (Ghent system).

12. An adjustment is made to allow for the fact that the average score of all the countries on each of the sub-indices varies somewhat, so as to ensure that equal significance is given to all six elements. For instance, the average score is rather higher than the notional average of 0.5 in the case of wages and rather lower for skill development. 
which figure slightly below the EU27 average. Indeed the continental countries are rather diverse, with Austria figuring in the middle of the upper distribution and Luxembourg, Belgium and the Netherlands close to the top. Both Englishspeaking countries are found above the EU average. The Nordic countries areall among the top performers, with Denmark doing by far the best as has already become evident in the discussion of the sub-indices.

Two important points for country clusters emerge from this brief discussion. Slovenia should not be bundled uncritically into the central and eastern European cluster as it displays characteristics that in many regards are rather similar to the corporatist countries or at least lie somewhere between the two country groups (see also Erhel et al. 2008; Keune 2010). The same is true of Malta and Cyprus which, at least in terms of job quality, are more similar to the continental countries than to the geographically closer southern ones (see also Leschke and Watt 2008: 29ff).

With regard to gender differences, caution is needed because the gender performance is quite different in some of the sub-indices, so the indicator value of their simple average is probably rather limited. With this caveat in mind, the first conclusion is that overall gender differences are rather small: the pluses and minuses in some indices, notably the two relating to non-standard contracts and working time and work-life balance, tend to even out. It seems that in countries at the bottom of the distribution women tend to be slightly better off than men. In the middle of the distribution men seem to be favoured somewhat, whereas on top no clear patterns emerge. The largest differences in favour of men are evident in Spain and Italy, whereas the largest differences in favour of women are recorded in Romania and Slovakia.

Figure 8 Overall job quality index

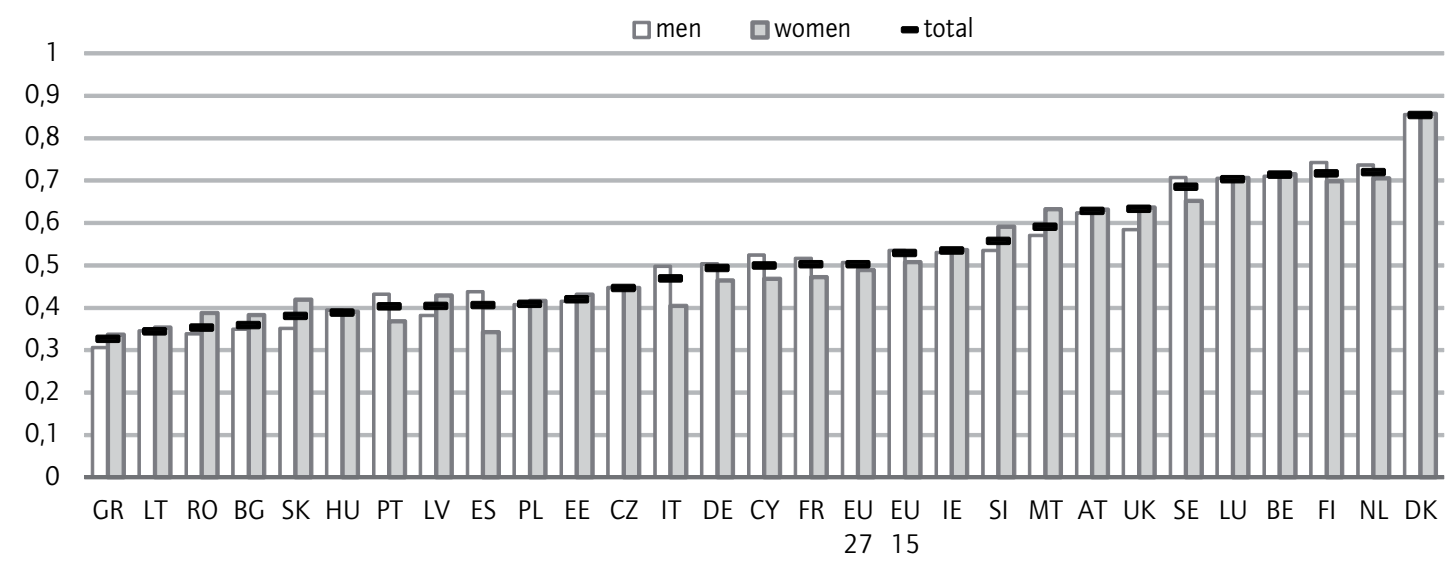

Source: own calculations

Note: un-weighted average of six sub-indices.

Annex 2 provides a summary of the findings in this section by country. It shows the ranking by sub-index for every country for totals, males and females using so-called radar charts. Countries have been ranked for each sub-index in such a way that the best performer scores 27 , the worst performer 1 . This means that 
the larger the area encompassed by the lines the better is the job quality. By way of illustration, the contrasting figures for Denmark, the best performer overall, and Greece, the worst performer, can be seen here (Figure 9).

Figure 9 Country rankings for sub-indices 2010: comparison Denmark (best performer) and Greece (worst performer)

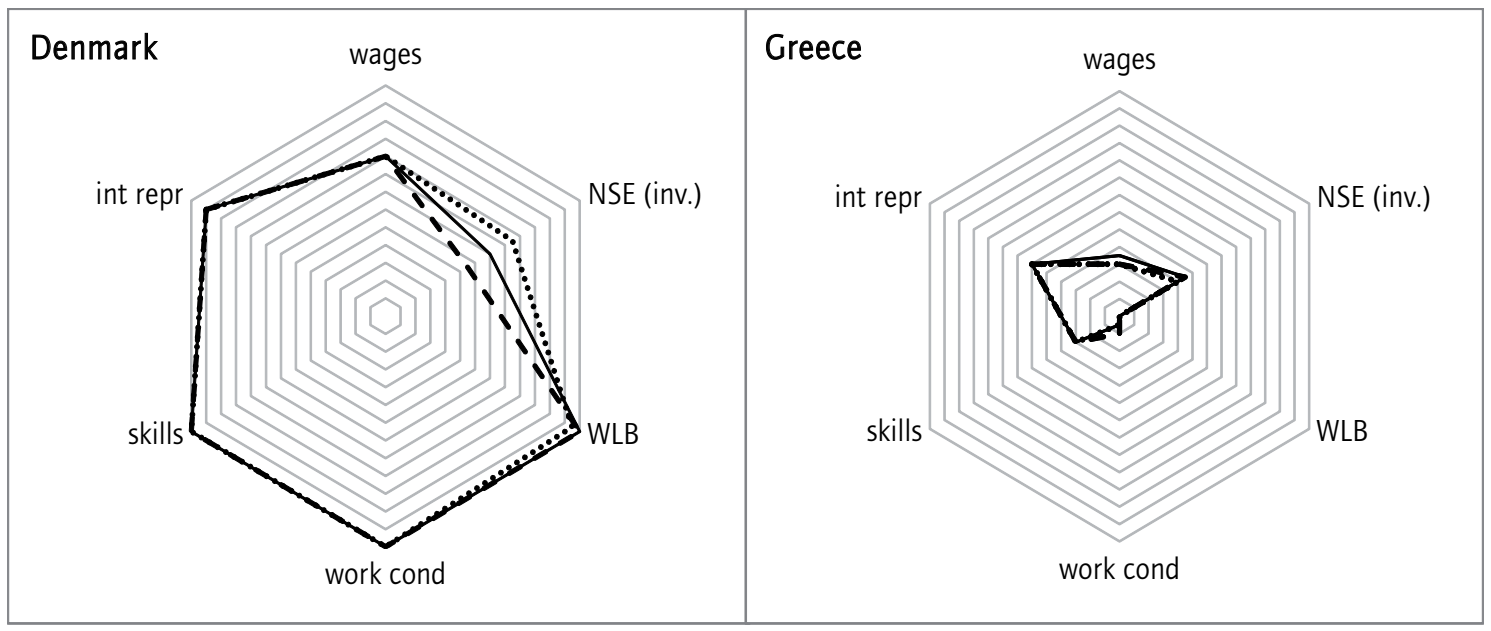

Source: own calculations

_ total ...... men _ - women

WLB: Working time and work-life balance NSE: non-standard employment

\section{Developments between 2005 and 2010}

This section discusses the changes in job quality between 2005 and 2010, not least in the light of the economic crisis that swept Europe from 2008 (already in 2007 in some countries). It is important to emphasise, however, that the results concerning changes injobqualityin itsvarious dimensions cannotbeinterpreted as simply reflecting the impact of the crisis. They also reflect developments before the crisis (2005-2008) which differ between countries and were, in a number of cases, characterised by an economic boom and sharply tightening labour markets. Moreover, the findings also reflect longer-term secular trends (such as tertiarisation).

In order to evaluate the performance of countries on the various dimensions of job quality over the 2005 to 2010 period, it is useful to begin by recalling the differential impact of the economic crisis of 2008 onwards on the economies and labour markets of EU countries (see also Leschke and Watt 2010) and also the period immediately prior to the crisis. 
Figure 10 Real GDP, \% change in national currencies, 2005-2010 and 2008-2010

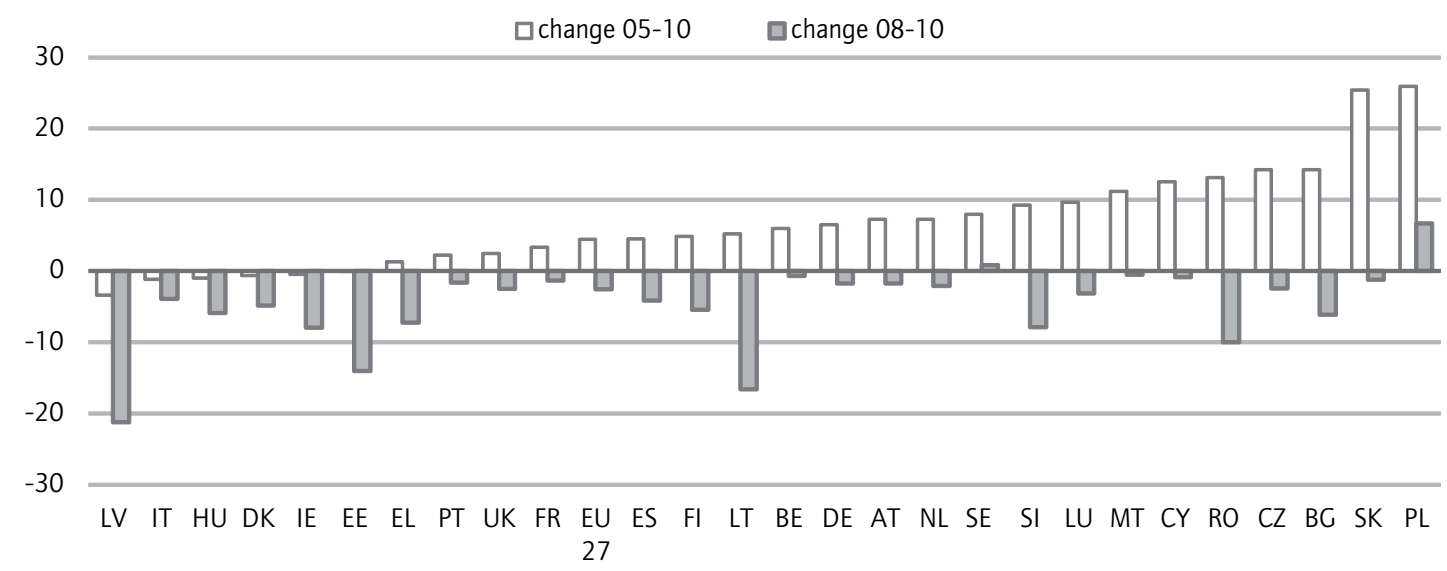

Source: own calculations.

Figure 10 shows that apart from six countries (Latvia, Italy, Hungary, Denmark, Ireland, and, just, Estonia) most EU countries did enjoy economic growth over the period as a whole. The best performers were all countries that entered the EU in 2004 or 2008, led by the spectacular performance of Poland and Slovakia where real output (in national currency) increased by around one quarter. A number of other CEE countries performed very poorly, however. For the rest, regional patterns are rather unclear, except for the notable underperformance of the southern European countries. Focussing on the crisis period alone, the picture is very different. Between 2008 and 2010 only two countries, Poland and (just) Sweden, managed any economic growth. In the others the scale of the contraction was especially high in many central and eastern European countries. Also hard hit were Ireland, the southern European countries, but also Denmark and Finland.

Figure 11 Unemployment rate, \%-point change, 2005-2010 and 2008-2010

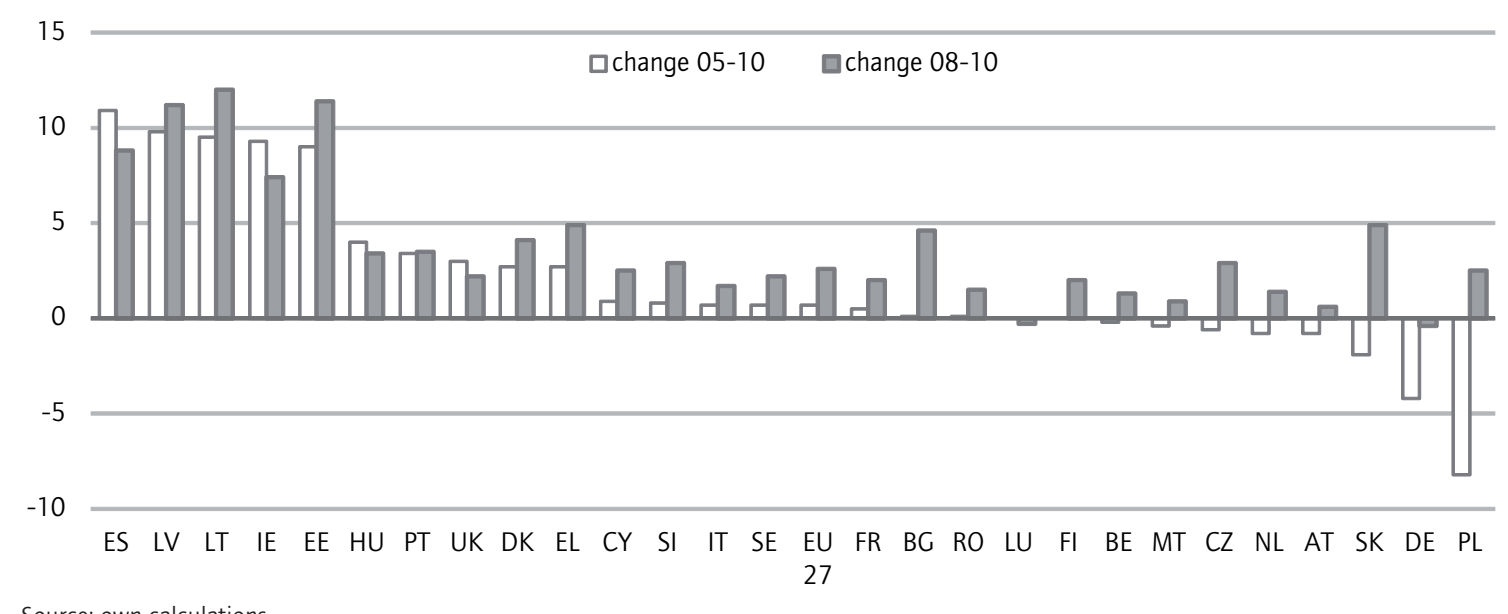

Source: own calculations 
Figure 11 shows similar results for the quantitative impact on EU labourmarkets as represented by changes in unemployment rates.

Again starting with the performance over the period as a whole, we see that eight countries managed to reduce the national unemployment rate between 2005 and 2010. Once again Poland was particularly successful but, additionally, Germany, Slovakia and Austria all saw substantial falls in unemployment. The overall rise in unemployment was most pronounced in Spain, followed by the Baltic states and Ireland. Hungary, the UK, Denmark, Portugal and Greece also saw substantial increases. This mostly reflected massive hikes in unemployment in the 2008-2010 period. It is worth noting, however, that there was also a sharp rise in unemployment in some countries during the crisis despite the fact that, in the period as a whole, they enjoyed declining unemployment (notably Poland, Slovakia, Czech Republic) or no overall change (Bulgaria).

This provides a framework against which to analyse developments in our indices of job quality.

Can we uncover a systematic relationship across countries between the recent labour market developments - driven substantially by the depth and duration of the crisis - and the developments in terms of job quality? Two hypotheses that are likely to lead to opposing impacts on job quality can be put forward: on the one hand, the rise in unemployment and the declining bargaining power of labour brought on by the crisis might be expected to have a deleterious effect on the quality of existing jobs. On the other, there may be compositional effects, specifically the more than proportional destruction of poor-quality jobs that actually push up averagenational job quality as measured by theJ QI. As they are of opposite sign it may be difficult to distinguish these effects using the aggregate data on which the J QI is based. The sub-indices are expected to differ in their sensitivity to the overall crisis impacts but also regarding the importance of the bargaining vs. the composition hypotheses. Some of the indicators (for instance in collective interest representation) are institutional in nature and thus likely to be slow-moving; crisis effects will not be anticipated in the short time span considered here. In other areas, lags are likely to be shorter (e.g. concerns about job security, discussed in section 4).

Looking at the average developments over time, we see a small overall decline in job quality (Figure 12). Improvements are visible with regard to working conditions (see section 4 for an in-depth analysis) and working time and worklife balance. On the other hand, marked deteriorations on the wages ${ }^{13}$ and the involuntary non-standard employment sub-indices were evident. Slight declines werealso visible in skills and career development and collective interest representation

13. It is important to note that the wage data in the '2005' J QI were actually from 2007; this choice was made at the time to ensure that the most up-to-date data available were used. In this case, the points made on various occasions below, that the period considered includes both 'boom' and 'bust' phases, does not apply. 
The disaggregation by gender - not shown - reveals only very small differences according to the six sub-indices and the overall JQI. The direction of change is the same in all cases. The decline in the overall J QI is slightly more pronounced among women and this reflected rather more pronounced declines or less pronounced improvement across all the 5 sub-indices that are gendered.

Figure 12 Changes in sub-indices between 2005 and 2010, EU27

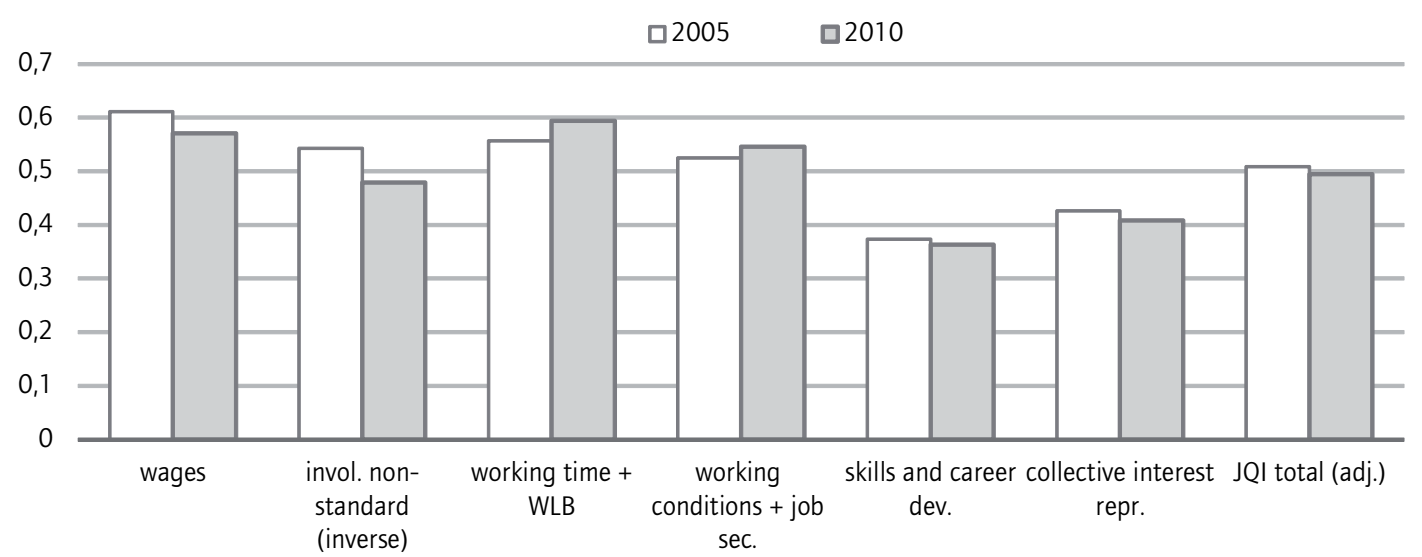

Source: own calculations

Figure 13 Developments in overall JQI by country, 2005-2010

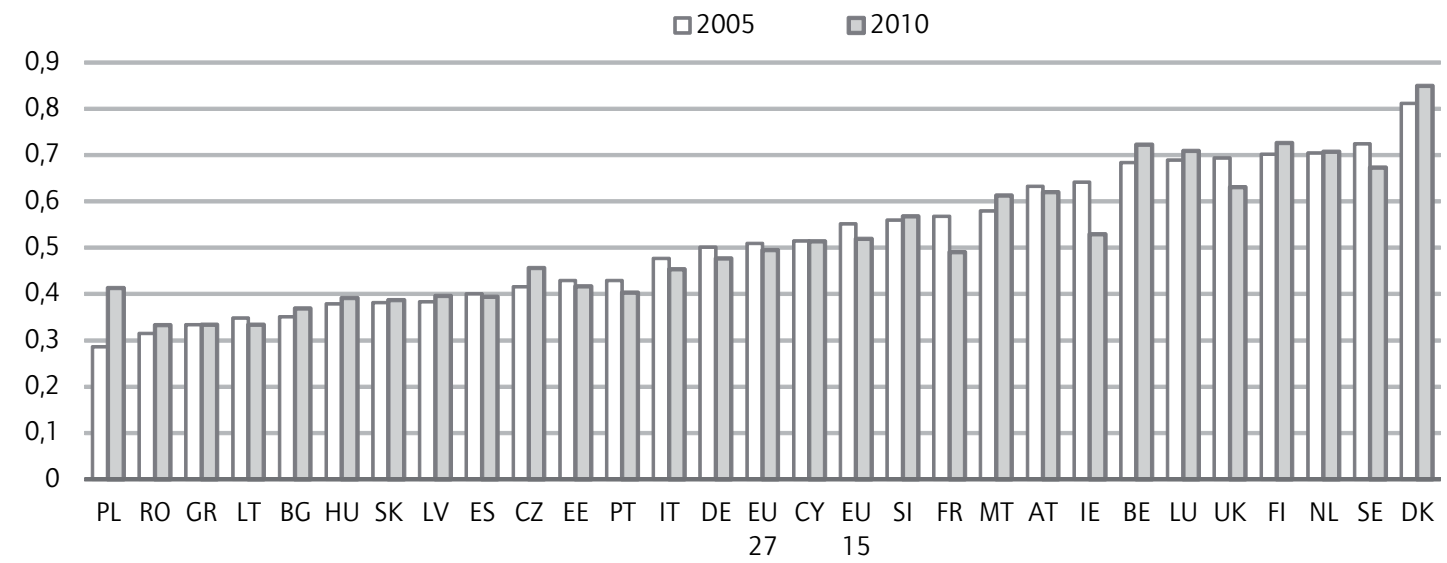

Source: own calculations

Figure 13 shows developments in overall job quality by country. We see the following countries with a more than marginal improvement in overall job quality (ranked by the absolute size of the improvement): Poland - with by far the largest improvement - Czech Republic, Belgium and Denmark. In contrast, Ireland and France saw marked declines in job quality. Across the distribution we do not see a clear pattern of either convergence or divergence of countries. This can be seen from, among other things, the fact that both the lowest and highest performing country in 2005 - Poland and Denmark - experienced substantial increases. Disaggregating changes in the J QI by gender does not, in most cases, reveal major differences. Notably those countries with substantial 
improvements or deteriorations tended to register a balanced development between men and women. ${ }^{14}$ Neither in regional terms nor in terms of the size of the economic crisis impact do we see clear patterns in terms of change in overall job quality. It follows that we should look in more detail at the individual subindices.

The most pronounced improvements and deteriorations according to the 6 subindices are summarised in Table 1. See Annex table 3 for the absolute changes for each country and sub-index. Cut-off points to demarcate the countries with thelargestimprovements and deteriorations were based on theabsolutechange. For each sub-index and for the overall J QI, the absolute change in the index for the EU27 is taken as a starting point. The cut-off points were then set at 0.1 points on the $0-1 \mathrm{~J}$ QI scale above (improvement) and below (deterioration) change in the respective EU27 figure. In the case of the overall JQI +/- 0.04 rather than 0.1 was used because the magnitude of changes in the overall index is smaller.

Table 1 Most pronounced improvements and deteriorations in JQI total and sub-indices - 2005-2010

\begin{tabular}{|c|c|c|c|c|c|c|c|}
\hline & wages & $\begin{array}{r}\text { involuntary } \\
\text { non-standard } \\
\text { (inverted) }\end{array}$ & $\begin{array}{r}\text { working time and } \\
\text { WLB }\end{array}$ & $\begin{array}{r}\text { working } \\
\text { conditions and } \\
\text { job security }\end{array}$ & $\begin{array}{r}\text { skills and career } \\
\text { development }\end{array}$ & $\begin{array}{r}\text { collective } \\
\text { interest } \\
\text { representation }\end{array}$ & $\begin{array}{r}\text { JQI } \\
\text { total }\end{array}$ \\
\hline improvement & IE & $\mathrm{PL}, \mathrm{BE}, \mathrm{LT}$ & RO, PL, LV, SK, HU, BG & $\mathrm{CZ}, \mathrm{PT}, \mathrm{PL}, \mathrm{DE}, \mathrm{FI}$ & $\mathrm{LU}, \mathrm{PL}, \mathrm{CY}, \mathrm{EE}, \mathrm{BE}$ & & $\mathrm{PL}, \mathrm{CZ}, \mathrm{BE}, \mathrm{DK}$ \\
\hline deterioration & $\mathrm{RO}, \mathrm{DE}$ & IE, IT, UK & $F R$ & IE, LU, FR, SE & $F R, S E$ & SK, PT, EE & IE, FR, UK, SE \\
\hline
\end{tabular}

Note: based on own calculations, only results for improvements and deteriorations of more than +/- 0.1 compared with the respective EU27 average are displayed. In the case of the Overall JQI, +/- 0.04 was used. Countries are displayed in the order of the magnitude of improvement and/or deterioration.

Few countries show marked improvements or deteriorations in more than one sub-index, exceptions being Poland, France and Sweden, Belgium and Ireland. Poland, the country with the largest total improvement, is a clear-cut example with marked improvements in all sub-indices but wages and collective interest representation. The other three countries that show marked improvements in overall job quality have very different profiles. Belgium improves markedly on both involuntary non-standard employment and skills and career development. The Czech Republic shows marked improvements on working conditions and job security. Denmark, while not figuring in any of the leading groups in the six sub-indices, is, however, very close to this group with regard to three subindices (working time and WLB, working conditions and job security and skills and career development) (annex 3).

France, the country with the second largest decline in overall job quality, shows marked deteriorations in three fields: working time and work-life balance; working conditions and job security; skills and career development. Sweden displays noticeable declines in two fields - working conditions and job security,

14. However there are a few exceptions. In Malta, Luxembourg and Bulgaria the improvement in the JQI and in Lithuania the deterioration was due solely to women. In the Czech Republic the improvement was almost only amongst men. In Spain and Hungary, while overall job quality rose for men, it fell for women; Slovenia experienced the reverse (not shown). 
and skills and career developments. The UK, also one of the worst performers overall, shows extreme negative developments only with regard to involuntary non-standard employment. With the exception of wages, developments over time were, however, negative in all sub-fields of job quality (annex 3). Ireland, the country with the largest negative development in overall job quality, is an interesting case in that it combines deteriorations of large magnitude in two fields - involuntary non-standard employment and working conditions with improvements in terms of the wages sub-index.

Figure 14 compares the two countries that mark the extremes in terms of developments over time - Poland and Ireland. Poland indeed improved across all the sub-dimensions - albeit from a very low starting point, as Poland was the worst overall performer in 2005. As already described above, developments in Ireland were more varied, with stark deteriorations in both involuntary non-standard employment and working conditions and job security, some deterioration in collective interest representation, but improvements in the wages ${ }^{15}$ and the working time and work-life balance sub-index. It is also evident from Figure 14 that, in spite of the opposite developments over time, Ireland is still doing substantially better on overall job quality and on the majority of subindices with, however, Poland now doing better on involuntary non-standard employment and on working conditions and job security.

Figure 14 Developments 2005-2010 in overall JQI and sub-indices for contrasting cases of Poland and Ireland

$\square 2005 \square 2010$

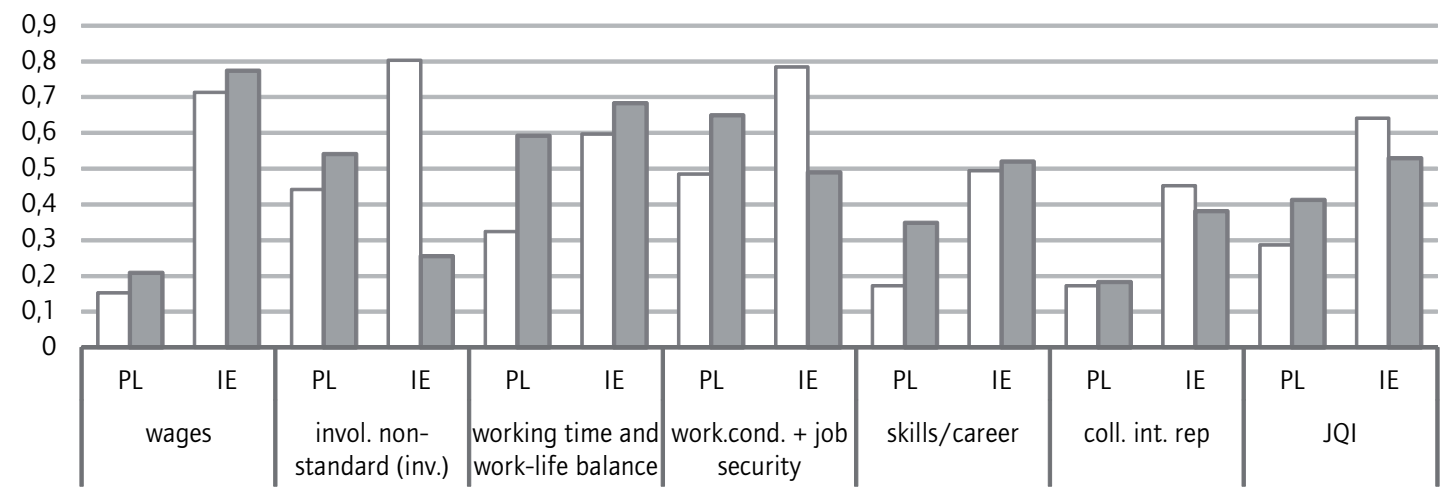

Note: based on own calculations.

We now broaden the discussion beyond the most pronounced improvements and deteriorations and consider somewhat more broadly the results in each sub-index - details of which can be found in annex 3 - in the light of the discussion above about the differential impact of the economic crisis on growth and unemployment. While some suggestive linkages do emerge, there is no

15. In the case of Ireland, the improvement in 'wages' largely reflects the fact that, while in Europe as a whole the share of working poor - which is $30 \%$ of the sub-index - rose, in Ireland it fell. This may also be a compositional effect (job losses at the bottom, income losses at the top of the wage distribution). 
consistent overall picture. Most obviously, the country with the largest job quality improvement according to our index, namely, Poland, also enjoyed the strongest real economic growth and the sharpest fall in unemployment. This is suggestive of the idea that quantitative and qualitative improvements are complementary and probably reflect a mixture of technological upgrading, sectoral change and an improvement in workers' bargaining power. Conversely, Ireland, the country which suffered the sharpest fall in the JQI, was one of the countries worst hit by the crisis.

The pattern of change in quantitative terms and our overall measure of job quality is not consistent, however, as the other three countries that substantially improved their performance between 2005 and 2010 illustrate. Belgium and the Czech Republic were negatively affected by the crisis to a below average extent, but Denmark, the best performer overall in 2005 and 2010, saw very little economic growth and experienced a substantial rise in unemployment over the period. To the extent that bargaining power is a factor, it may be that there are lags in the transmission from 'quantity to quality': Denmark had enjoyed prior to the crisis an extended period of close to full employment whose impact on quality may have been initially maintained despite rising unemployment; alternatively, an offsetting composition effect may have been at work. At the other end of the distribution, France, with the second most pronounced decline in job quality, had economic and labour market impacts in 2005-2010 that were very close to the EU27 average. And it is noticeable that many of the other countries hit hardest by the crisis (Spain and the Baltics) showed rather minor declines in the overall J QI (Latvia even showed a small increase).

Nevertheless, if we correlate the change in the unemployment rate between 2005 and 2010 with the changein the overall J QI, the following picture emerges:

Figure 15 Change in the unemployment rate between 2005 and 2010 and change in the overall JQI, 2005-2010

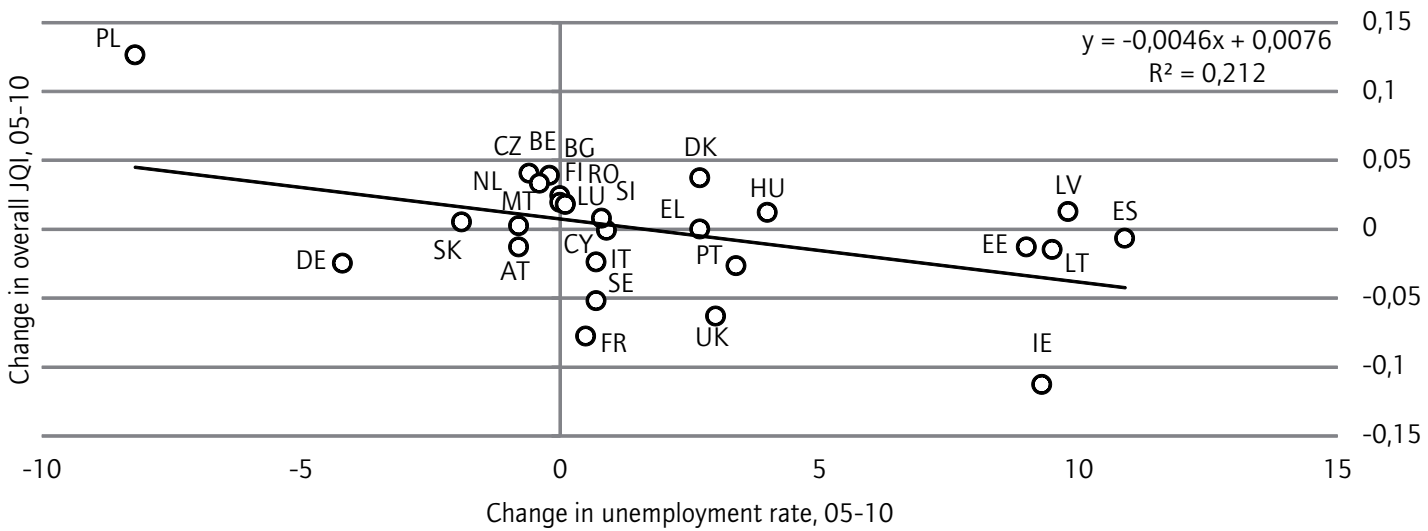


Although the relationship is quite weak in statistical terms, generally those countries which have seen stronger falls (or weaker increases) in the unemployment rate have been those in which measured job quality has improved (or declined less). On the whole, then, the bargaining power effect appears stronger than the compositional effect.

Turning now to the sub-indices broadly confirms this picture. There does appear to be some link between the size of the economic and labour market shock and job quality performance on the various aspects of job quality, but it is rather tenuous and, as hypothesised above, is stronger for some sub-indices. It seems plausible again to invoke differential lags as a likely explanation.

With regard to the wage sub-index, little correlation between quantitativelabour market developments and this aspect of job quality emerges. Countries with the greatest positive change includeboth Poland and Ireland, with entirely different economic and labour market developments. (As noted above, in the case of Ireland the distributional component played an important role.) At the other end of the scale we have crisis-hit countries such as Greece, but also Germany. As mentioned above the wages comparison is 2007 to 2010 . This is too short a period to identify meaningful trends, especially given the lags involved.

In the case of non-standard employment, the relationship does, however, seem rather clear-cut. The worst deteriorations are to be found in the southern periphery and in Ireland and the UK. The greatest improvements were among countries with, relatively speaking, favourable economic and unemployment trends (Poland, Belgium, Finland Luxembourg and Germany). This is confirmed by a positive statistical correlation (not shown) that is stronger than for the overall JQI $\left(\mathrm{R}^{2}=0.27\right)$.

Both involuntary temporary employment and involuntary part-time employment contributed to the large decline in the involuntary sub-index in Ireland, Italy and the UK. This suggests that in these countries employers enforced working time reductions and/or made increased use of fixed-term contracts that were seen as negative from the workers' perspective. In Spain, by contrast, other work by the authors (Leschke and Watt 2010) showed very large composition effects: fixed-term workers, in particular, bore the brunt of the labour market adjustment, with the consequence that their share of total employment declined substantially. The countries with marked improvements in this sub-index had more varied patterns. Poland, with a tightening labour market over much of the period, saw a fall in the part-time share with more workers taken on in full-time positions and, presumably, some conversion of part-time to full-time jobs. In addition, fewer of these part-timers reported that they could not find a full-time job.

In the case of working time and work-life balance, it seems more that a secular and regionally specific trend is important: all the substantial improvements occurred in CEE countries - with improvements across all the four indicators in virtually all cases. There has been a fall in the incidence of excessive and anti- 
social working hours, whereas the two indicators that try to capture work-life balance show a consistent improvement. This may reflect that companies in crisis havereduced over-timeand scrapped extrashifts. Declines wereregistered only by western European countries (this is also evident from the large gap in the ranking between the EU15 and EU 27 aggregates.). The three countries with the biggest declines are countries with a relatively favourable (Germany), average (France), and unfavourable (Greece) experience over the 2005-2010 period; the crisis seems not to have had a consistent impact on this dimension.

Moving to skills and career development (working conditions are dealt with in detail in the next section), we see that both the improvers' group and the group of those suffering a decline in this aspect of job quality contain countries badly and relatively lightly affected by the crisis (Estonia and Poland, and Lithuania and Sweden respectively). The same conclusion can be drawn for collective interest representation, an institutional variable that is relatively slow moving.

\section{Detailed analysis of the sub-index 'working conditions and job security'}

We will now look in more detail at the sub-index 'working conditions and job security' in onder to uncover some of theimpacts of labour market developments, in particularly in light of the crisis. It is important here to emphasise once again that we are not looking exclusively at the crisis period because the EWCS data on which this sub-index is based allows us to look only at changes between 2005 and 2010, catching also the tail of the pre-crisis boom in many countries. The working conditions and job security sub-index is composed of four indicators: work intensity, work autonomy and physical work factors - all three being based on a list of items - and the item 'not worried about losing my job in the next six months'.

Particularly the latter variable, which picks up 'subjective job security', is expected to be impacted directly by rising unemployment. And indeed, not only does the overall level of unemployment matter (Figure 16) but there is also a strong negative correlation between the changes in unemployment and the changes in the share of people not worried about losing their job (Figure 17). ${ }^{16}$ Germany and Poland, the countries that experienced the most marked declines in unemployment in the period 2005 and 2010, are the only countries where the share of people not worried about job security increased noticeably. The opposite is true for the Baltics, Spain and Ireland, all of which doubled or, in the case of Ireland, tripled their unemployment rate between 2005 and 2010, and particularly during the economic crisis; and during the same period saw the share of people not worried about losing their job decline by around 30\% and - in the case of Lithuania - close to $40 \%$. These findings are the clearest illustration of our 'bargaining power hypothesis' where quantitative labour market developments bring same-sign changes in qualitative indicators. 
Figure 16 Unemployment rate and share of people 'not worried about losing job', 2010

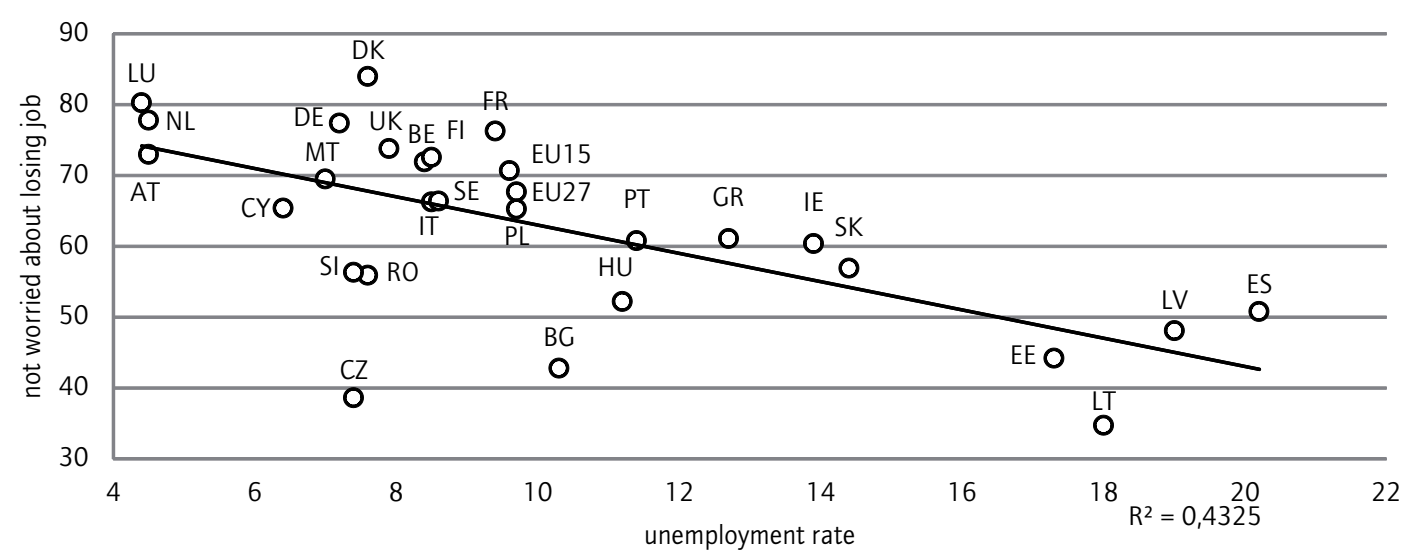

Source: own calculations based on LFS and EWCS data.

Figure 17 Changes in unemployment rate and changes in share of people 'not worried about losing job', 2005-2010

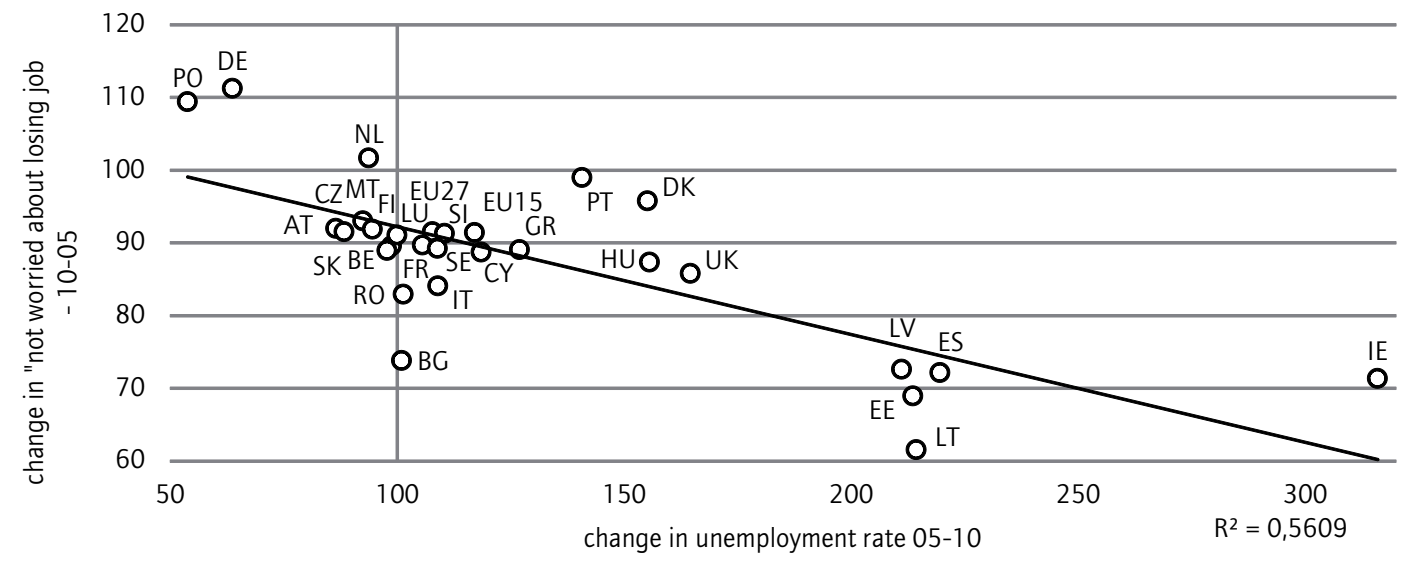

Source: own calculations based on LFS and EWCS data.

The other three indicators of this sub-index are also likely to be impacted by the recent labour market developments. The impact can either be direct, e.g. in the case of 'work intensity' where we expect that work has become less intense over the last couple of years as the orders situation of firms deteriorated during the crisis and many companies resorted to short-time working and other worksharing measures. Or the impact can be more indirect due to crisis-induced changes in the sectoral or educational composition of the workforce - this is likely to bethecasefor physical work factors and work autonomy. Changes in the latter indicators would serve to reinforce our compositional effect hypothesis. If - as was evident particularly in the first phase of the crisis - manufacturing and construction jobs are lost disproportionally, this is likely to positively impact the physical work factors sub-dimension, and possibly also work autonomy, by removing thosejobs with the worst quality on this dimension. 
The subsequent section will examine in detail how the four indicators that make up the sub-index contribute to the changes over time. Additionally, for the 'work intensity' indicator, we break the results down further to the level of the single variables that compose this indicator. The analysis focuses on the EU27 average as well as two of the worst performing and three of the best performing countries in terms of developments in this sub-index. The countries arealso characterised by different exposure to the crisis. Ireland was doing very well on this sub-index in 2005 and saw very large declines in 2010; at the same time, the crisis had severe labour market outcomes. France was ranked above average in 2005 and also saw substantial declines in this sub-index; it was hit by the crisis but more or less in line with the EU average and much less severely than Ireland. On the other hand, Germany, Poland and Portugal, all performing below average in 2005, saw marked improvements in working conditions between 2005 and $2010 .{ }^{17}$ The latter country was affected rather severely by the crisis, whereas theimpacts were less visible in Poland and Germany which sawunemployment declining considerably despite having risen during the worst of the crisis.

Subjective job security was indeed the one single item of this sub-index which saw the largest decline (Figure 18). On EU27 average, the share of people not worried about losing their job decreased by more than 8 percentage points. On the contrary, but also in all likelihood an effect of the crisis, the share of people that report medium to low work intensity has increased by roughly $6 \%$, implying an improvement in job quality. On the other two dimensions, changes were much less pronounced - physical work factors remained almost constant on average while work autonomy increased by roughly $3 \%$, the latter most likely a composition effect and possibly partially reflecting a longer-term trend. All changes were more marked for men than for women, which is in line with the gender differences in unemployment developments during the early years of the crisis.

Looking at our selected countries, both Ireland and France saw declines in all four sub-dimensions and most so in subjective job security - this was by far the most important dimension for both men and women in Ireland, whereas in France declines in work autonomy were most important in the overall declines in working conditions for women while declines in subjective job security were by far most important for men. Overall, gender differences were much more pronounced in France than in Ireland. In Germany, Poland and Portugal job quality in the area of working conditions increased, overall. A first interesting outcome is that subjective job security increased markedly for both men and women in Germany and Poland and for women in Portugal. This is in stark contrast to all other countries, with the exception of the Netherlands. Additionally, in all three countries, the share of people with low work intensity and high work autonomy increased; this was less the case for physical work factors. Gender differences again are visible but with no clear pattern.

17. The Czech Republic, which was the country with the largest overall improvements in this subindex, is disregarded here due to lack of space. Its profile with regard to developments in this sub-index is similar to that of Portugal but somewhat more pronounced. 
Figure 18 Working conditions and job security sub-index: changes in indicators 2005-2010
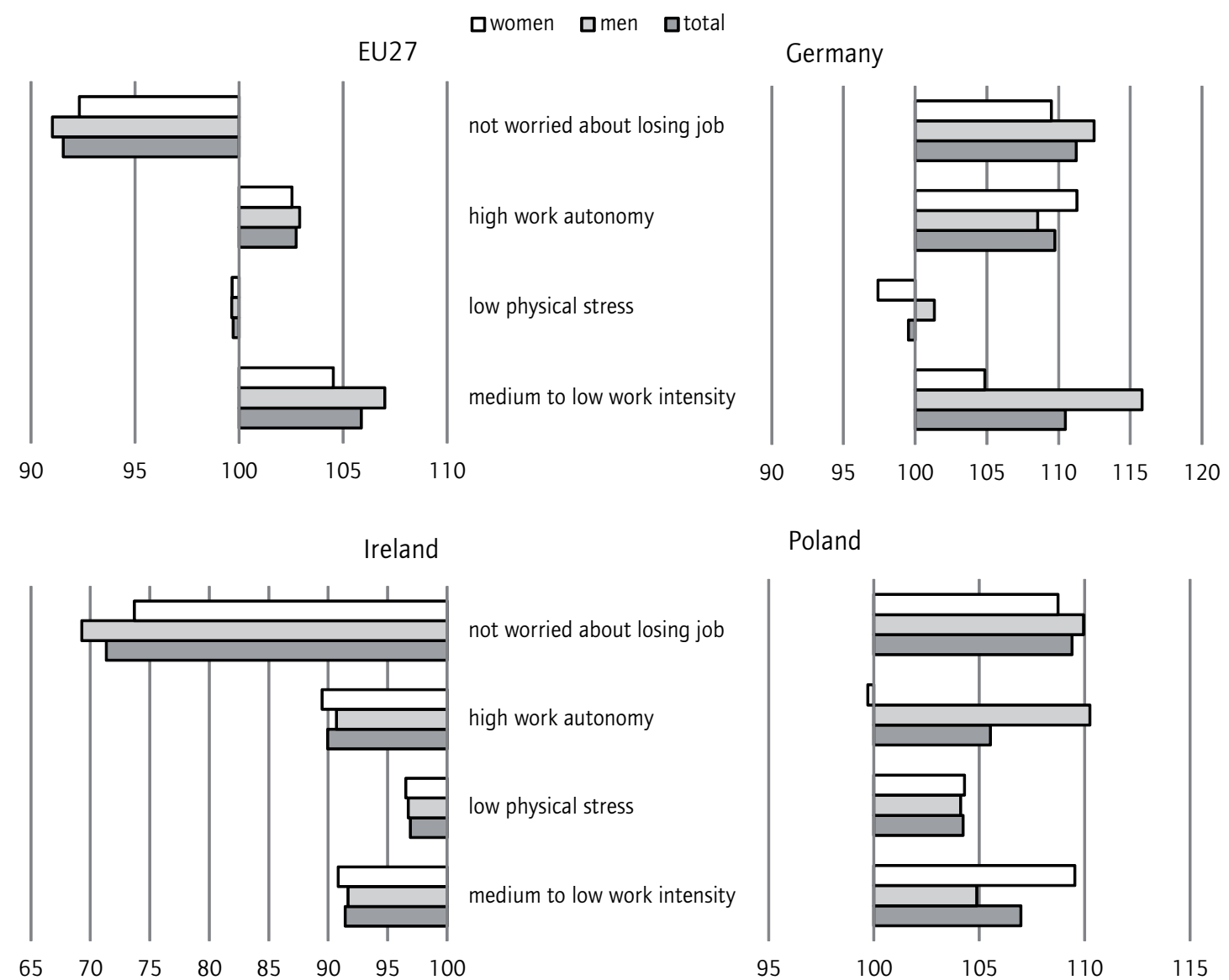

Poland
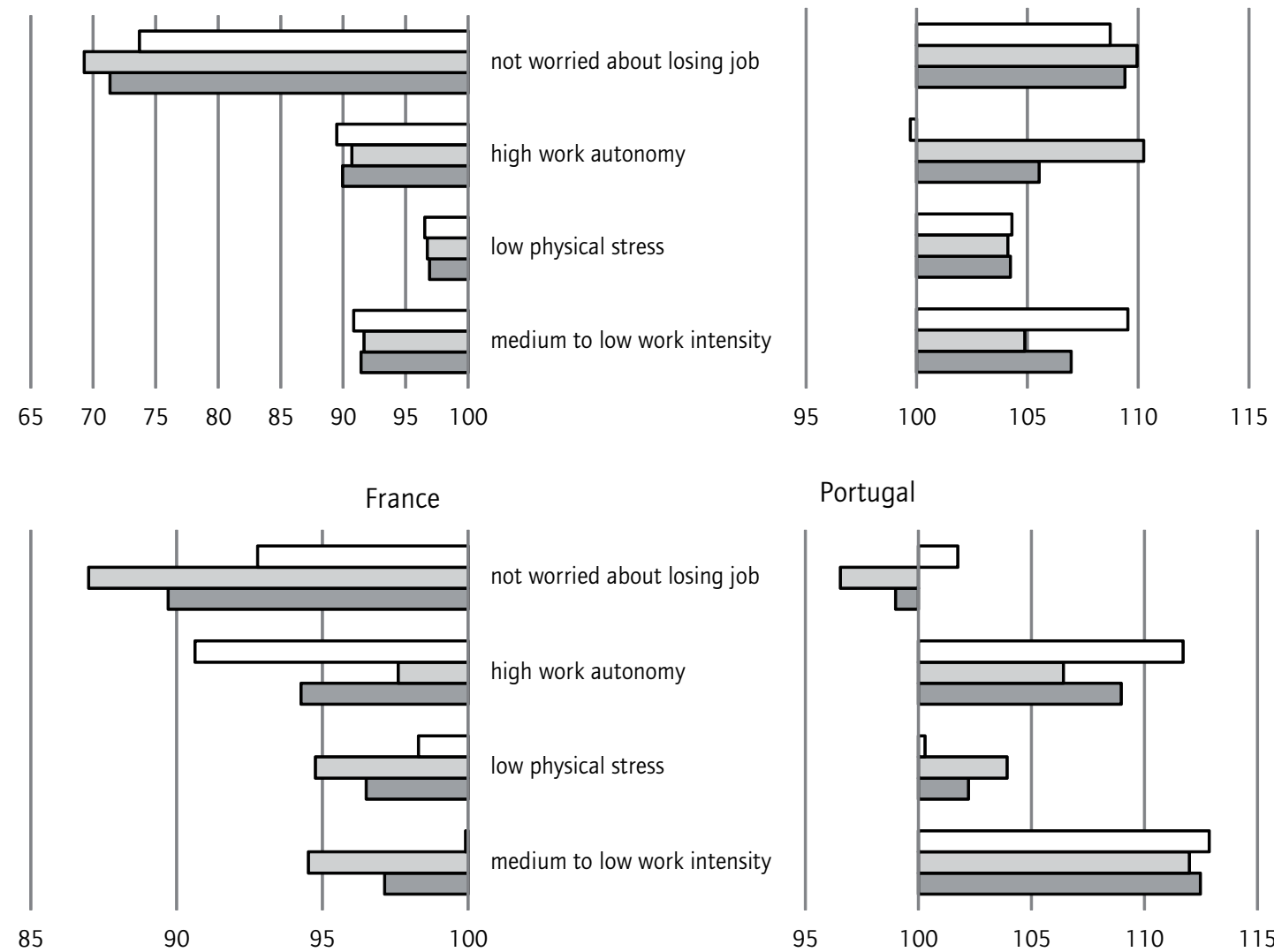

Portugal

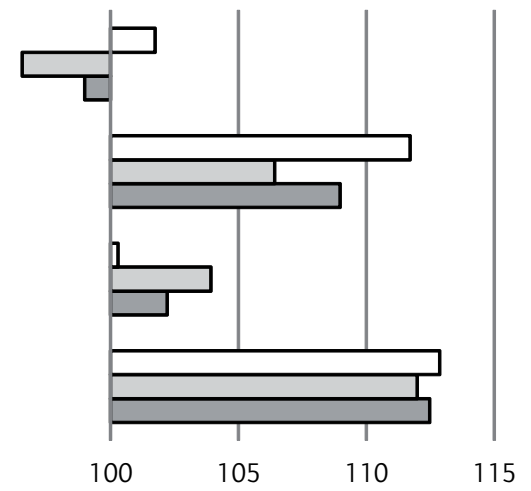

Source: own calculations 
We now look in more detail at the work-intensity indicator as this is the area where we saw the largest positive developments on average but negative developments in both of the countries that showed marked declines in total working conditions. First of all, it is important to stress that only four countries, and among them Ireland and France, saw the share of people with low work intensity declining - and only in Ireland was this decline substantial. On the other hand, more than half of all countries saw the share of people having low work intensity increasing by at least 5 percentage points; the Czech Republic, Denmark, Germany, Spain, Portugal, Austria and Finland all saw changes in this variable of more than 10 percentage points with no clear gender patterns (not shown). As these countries differed markedly regarding the impact of the crisis, it seems that the impact of the crisis on this aspect of job quality has been ambiguous or weak.

Figure 19 shows how the different variables of this dimension contribute to the overall outcomefor the EU27 average and our selected countries. On average, all dimensions, but especially 'enough time to get the job done', sawimprovements with men showing considerably more upward trends than women. This could be interpreted as being in line with the fact that, at least in the first period of the crisis, men were more strongly affected by labour market impacts of the crisis such as reduced hours. Ireland, with increasing work intensity for men and women and France with increasing work intensity for men, saw an increasingly marked incidence of 'working at high speed' and 'working to tight deadlines', whereas, at least in Ireland, considerably more people said that they had 'enough time to get the job done'. Germany, Poland and Portugal saw positive trends on all three indicators. Neither do we see a clear predominance of one of the three variables of this dimension, nor is the gender impact moving in the same direction across countries.

To conclude, there is some evidence that composition effects have statistically served to raise job quality in this dimension, while the economic slack, whatever its other negative impacts, has in many cases reduced stress and pressure at work, at least for someworkers. At the sametime, therather positive experiences in Germany and especially Poland, and the negative trends in Ireland, are in line with the bargaining power hypothesis in which good (bad) labour market developments exert upward (downward) pressure on job quality. All in all, it turns out to be rather difficult, however, to judge more fully the impact of labour market developments, and more particularly the crisis, on this sub-index, as there are too many contributory factors that are not easy to disentangle. One possibility for future research is to use the EWCS micro-data and control for sector and education effects - relatively low case numbers will, however, impedein-depth analysis by country. It would also be helpful in many countries to have data for 2007 or 2008 - which however are not available due to the five-year interval between EWCSs -, the point which the crisis broke, as the 2005-2010 observation period may be having the effect of averaging out (and thus obscuring) the impact of good and bad labour market trends before and after the onset of the crisis. 
Figure 19 Working conditions and job security sub-index - variables of 'medium to low work intensity' sub-dimension, \% change 2005-2010
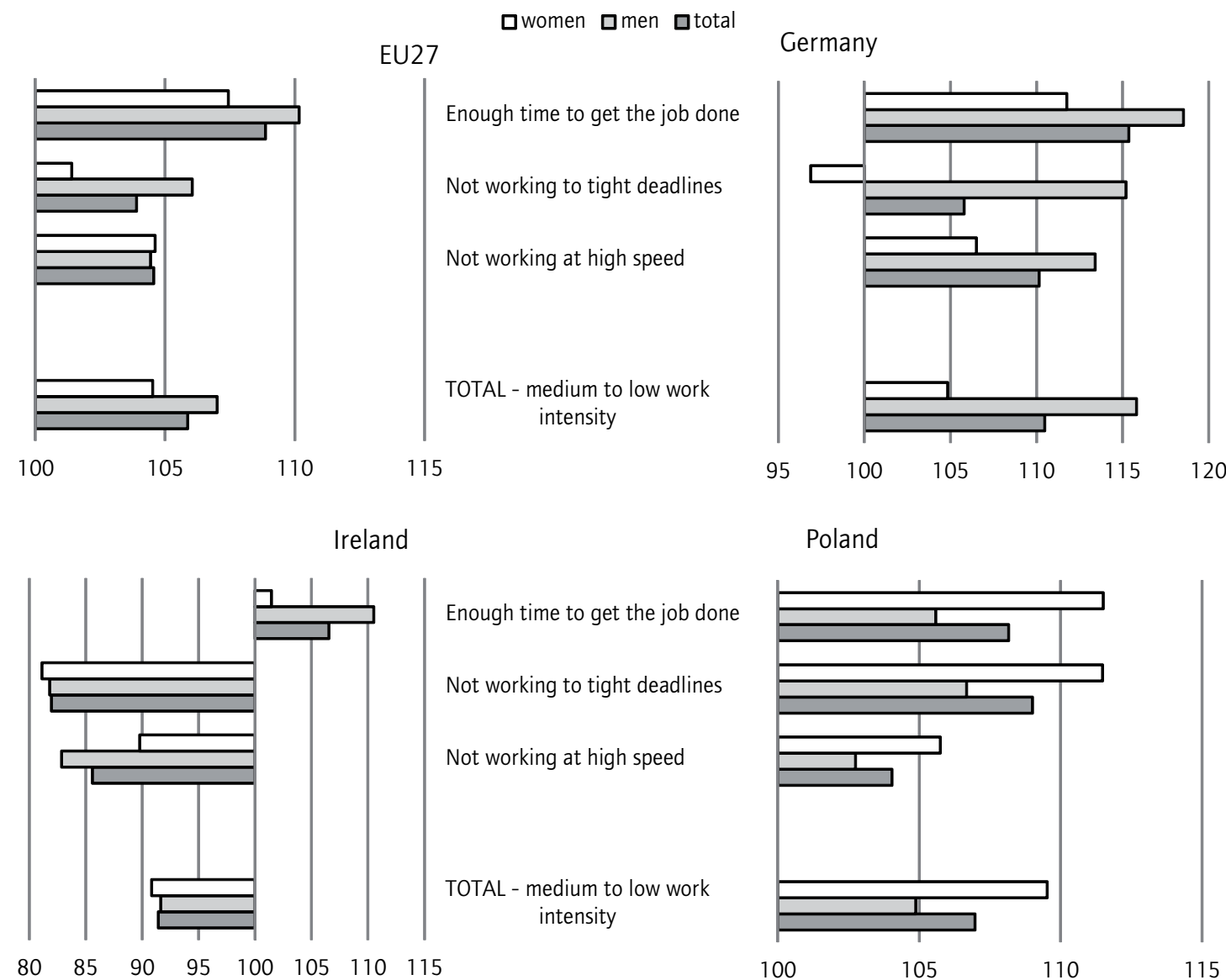

Poland

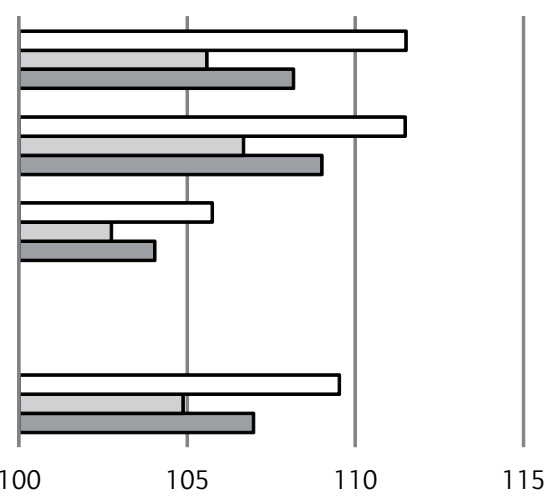

Portugal

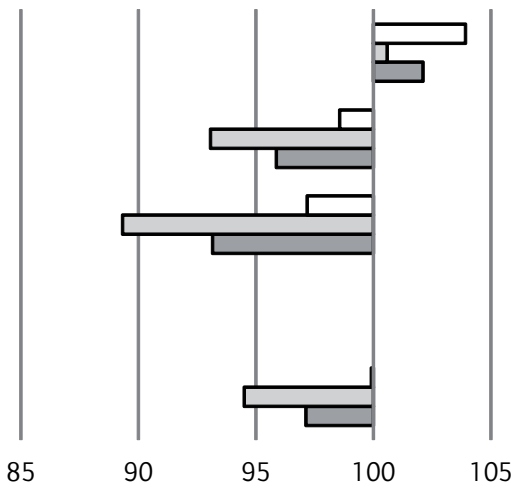

Enough time to get the job done

Not working to tight deadlines

Not working at high speed

TOTAL - medium to low work intensity

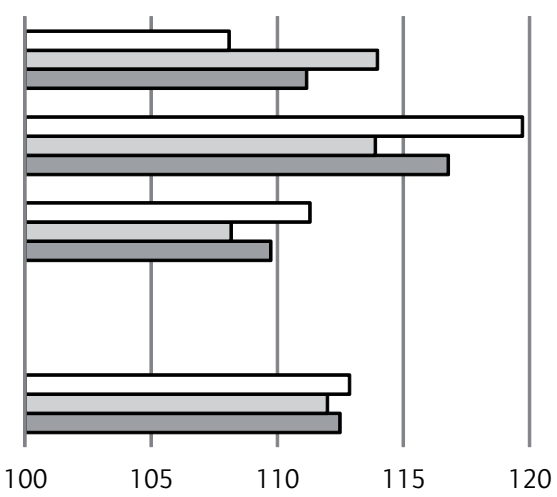

Source: own calculations.

Note: the variables are coded as follows: enough time to get the job done: often, almost always; working to tight deadlines: medium to low; working at high speed: medium to low. 


\section{Alternative specifications}

As has been emphasised at various points in earlier sections and also in early work by the authors (Leschke, Watt and Finn 2008; Leschke and Watt 2008), the construction of a composite indicator necessarily involves compromises and trade-offs. The decision to have data for each EU27 country that is updated at regularintervals limits theindicators that could beconsidered. Somedimensions of job quality are hard to pin down in terms of quantitative magnitudes. Value judgements may differ. Decisions on whether to include an indicator which is known to be less than optimal, or rather to leave it out and miss entirely a potentially important element, can be difficult. Since the publication of the first JQI, we have benefited from the feedback of numerous colleagues at academic conferences and on other occasions and have discussed the advantages and disadvantages of certain choices. In addition, new data sources have become available since 2008, which may shed an interesting light on our findings, even if they often cannot be used for a comparison with earlier scores. ${ }^{18}$

Reflecting all of this, in this final section we consider a number of alternative specifications for two of the six JQI sub-indices: wages, and working time and work-life balance. In each case, we briefly discuss the arguments for and against changing the specification and present some evidence as to the effect of such alternative specifications on the outcomes. We conclude with a discussion of some new indicators for the collective interest representation and working conditions andjobsecuritysub-indices which havemeanwhilebecomeavailable.

\section{Wages}

In 2008 the wage data in the EU-SILC survey was not available for all EU27 countries and wage data werenot availablein the European Labour Force Survey data. Instead we used gross wage data from the national accounts expressed in purchasing power standard (from the AMECO database of the European Commission). While this had a number of advantages, two main concerns remained. One is that the figures are expressed per employee. They do not allow for differences in working time or, for the comparison over time, for any rise in part-time work. The second is that the gross wages include elements that do not, at least not directly, benefit workers and, more importantly, differences in the way that social security systems are financed may distort the cross-country comparison.

In principle (gross) earnings data are now available from Eurostat that resolve the part-time/ full-time problem, as the data can be disaggregated. This data is based on firm surveys. However, in most countries their coverage is limited to workers in firms with at least 10 employees and, worse still, the requisite data are not available at all for a significant number of countries (including Austria,

18. On this issue see also the discussion in Leschke/ Peña-Casas/ Watt (2011) on the challenges of constructing a European job index. 
Italy, Poland) and thus not for theEU aggregates, and in a number of others only for 2009. As a 'plausibility test' the latest figures on this measure (i.e. 2010 or 2009) are compared with our original measure based on the national accounts for the seventeen countries for which we have data; the figures refer only to the business economy (i.e. excluding public administration ${ }^{19}$ ).

Figure 20 compares the JQI measure with the alternative specification. Evidently, the two measures are highly correlated.

Figure 20 Comparison of JQI measures of wages (nominal compensation) and an alternative specification (gross earnings for full-time workers)

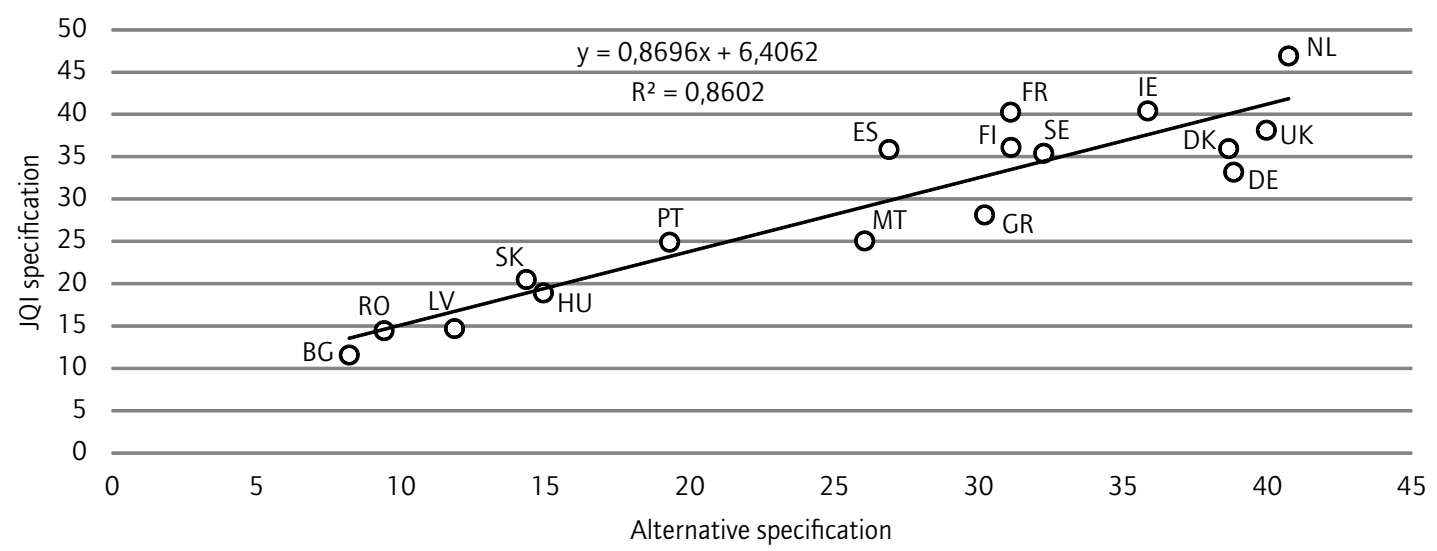

Nevertheless the alternative specification makes a considerable difference for some countries: Denmark, Germany and the UK, notably, perform better on this measure, while other countries, including Ireland, France and Spain, do less well on this measure. However, we cannot be sure that the alternative is superior. Notably it is not clear that the correction for the share of part-timers, which is the one strong argument for using this measure, clearly shows up in the results. On the contrary, it may well be that it is the exclusion of small firms from the sample that is the most important factor in the changes. Particularly given the large number of missing elements, the incomplete sectoral coverage and the lack of EU aggregates, this alternative specification turns out then to be unsatisfactory.

A separate set of series is available, based on household surveys, with both gross and net wages, and these are comparatively complete and up-to-date. The gross wages can be considered closer to employees' actual income than nominal compensation, used in the JQI, as they exclude a number of labour costs paid by the employer but not directly benefiting the worker. Here there are two problems. One is that the full-time/ part-time issue raises its head once again. The second is that the database does not indicate an average figure for

19. NACE sectors B to N. If the coverage of sectors is extended (B-S) the number of missing countries is so high as to make any comparison dubious. 
net or gross wages for each country, consistent with our approach in the J QI. Instead figures (both net and gross figures) are presented for various household types (single, married and unmarried, number of children, wage of primary and secondary earner as a proportion of national average, etc.). A choice of household type therefore has to be made.

Figures 21 and 22 show the relationship between theJ QI measureand gross and net wages, respectively, for a single person without children earning the average wage, this being the household category closest to the concept of theJ QI.

Figure 21 Comparison of JQI measures of wages (nominal compensation) and an alternative specification (gross earnings for single earner earning the average wage)

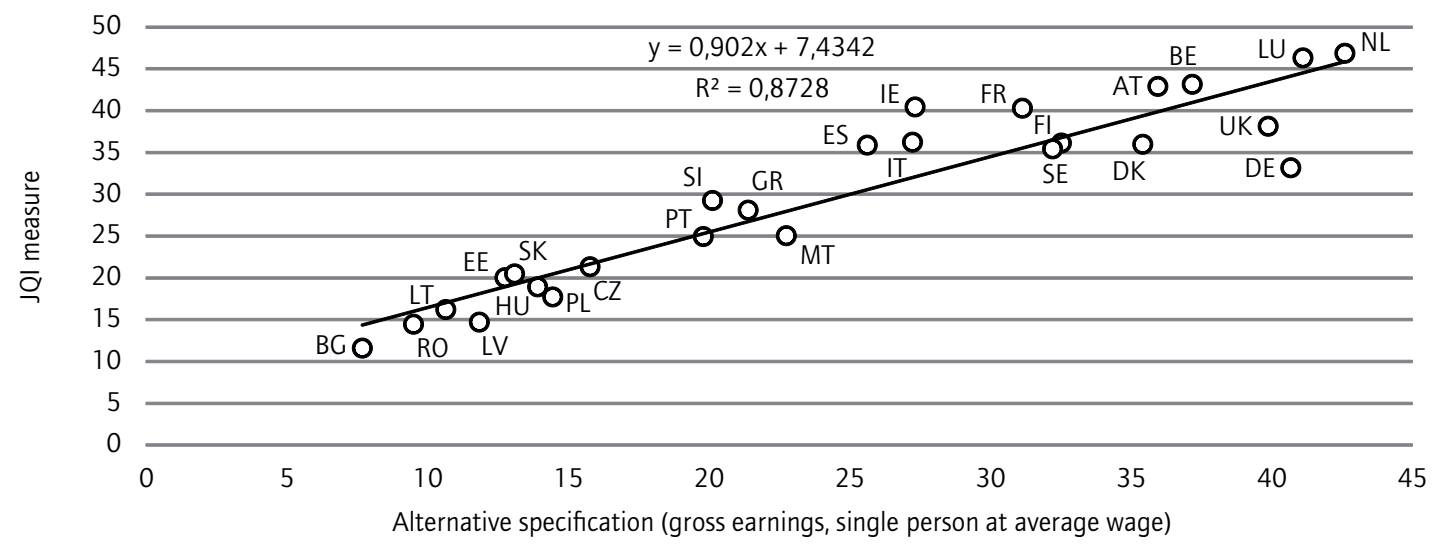

Source: own calculations.

Figure 22 Comparison of JQI measures of wages (nominal compensation) and an alternative specification (net earnings for single earner earning the average wage)

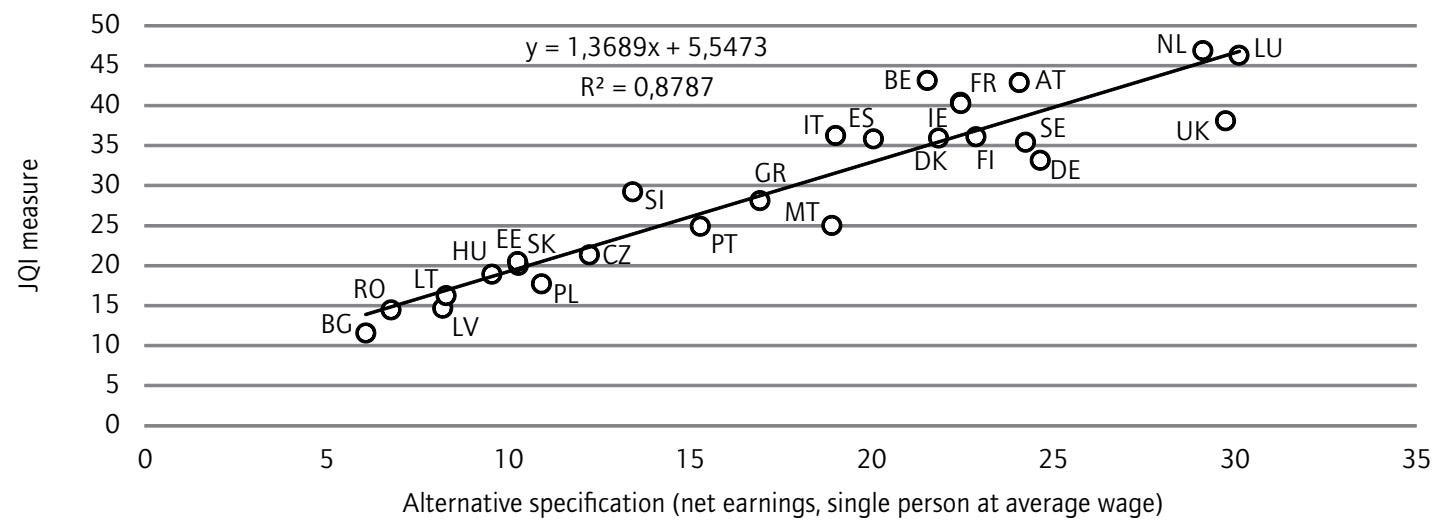

Source: own calculations.

As can be seen from the scatter plots and the high values of R2, the newly available Eurostat data on earnings and our JQI measure are very highly correlated. Shifting from average nominal compensation to gross earnings for 
a single employee at the average wage leads, in most cases, to a reduction in the values, but one that is rather even in relative terms (thus not affecting the normalised values). There are some exceptions, however. In Germany the figure for the alternative specification is actually considerably, and in the UK slightly, higher. Other countries (Ireland, Spain, France) perform rather worse on this measure than using our JQI specification. A similar picture emerges with regard to net wages. In addition to the countries already mentioned, Belgium emerges as a country that performs considerably worse on a net measure. However, it is not clear that 'net' is intrinsically a better concept than gross wages in terms of job quality. Social insurance contributions, notably, go to finance welfare benefits and public services from which workers (and other social groups) benefit, if only indirectly and this is relevant for national comparisons.

If we use the two alternative specifications ('gross' and 'net') and recalculate the JQI sub-index wages - in which, it is recalled, 30\% is accounted for by an (unchanged) distributional indicator - we get the results shown in Figure 23.

Figure 23 Comparison of JQI wage sub-index with two alternative specifications

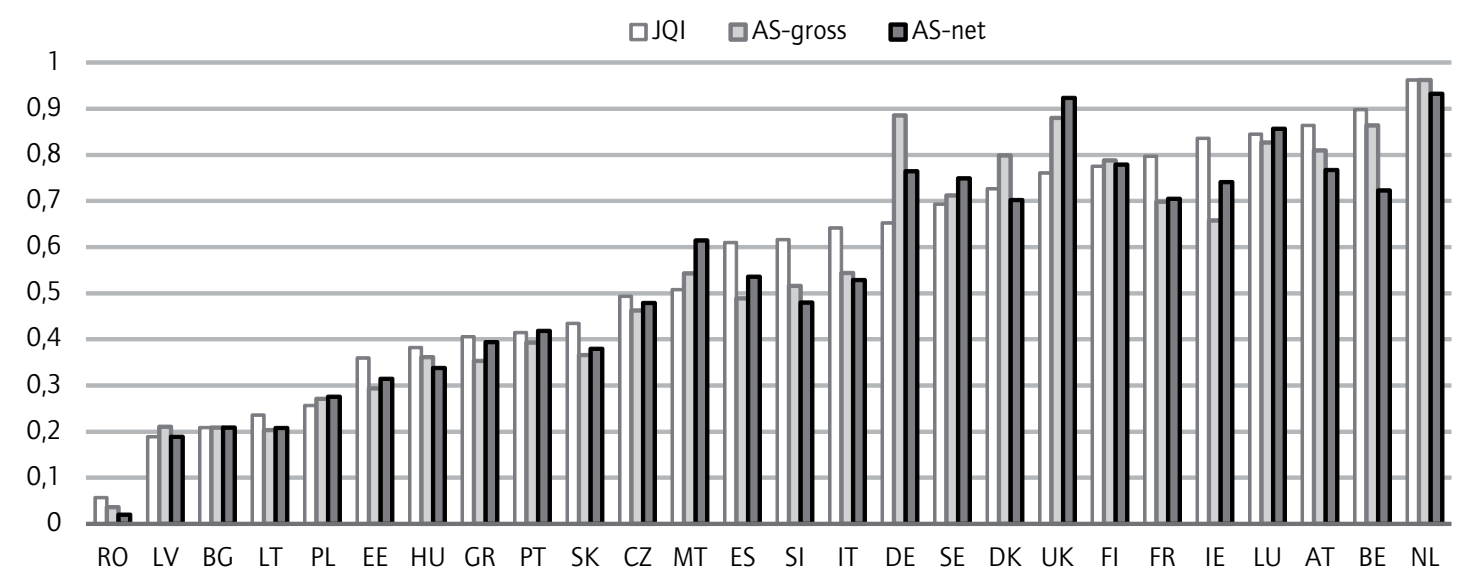

Source: own calculations

The figure confirms that the rankings on this sub-index would not be fundamentally changed by using alternative specifications. On the AS-gross measure, index deteriorations exceeding 0.1 points are recorded for Ireland, Spain, and Slovenia; improvements of the same magnitude are limited to the UK and Germany. In the case of the net measure, using the same cut-off, deteriorations emerge in Belgium, Slovenia and Italy, improvements in Malta, Germany and the UK.

The discussion of alternative specifications in the area of wages can be summarised as follows. Arguably there is not a single best metric. The JQI measure (nominal compensation per employee at PPS) has weaknesses, but so do other conceptions. Overall, the correlations between the indicators are quite high, but an altered definition would change the position of some countries. Yet the different alternative specifications do not appear to systematically favour or disfavour a readily identifiable group of countries. 


\section{Alternative specification on sub-index: working time and work- life balance}

Our original 'working time and work-life balance' sub-index contains four equally weighted indicators: excessive working hours, anti-social hours (week-end work, etc.) (both inverted), voluntary part-time work, and a more subjective assesment on the degree that working hours fit with family and social commitments. It has been argued, however, that not only excessive working hours, but also very low weekly hours, often coined marginal hours, are unpopular with workers (e.g. Fagan 2004). Very low hours are problematic, in particular as the earnings usually do not suffice to make a living independent of a complementary income (from a partner or welfare benefit). Similarly, these employment relationships usually carry a penalty in terms of entitlement to social benefits and particularly pensions that, in times of unstable relationships and high divorce rates and changing design of pension schemes (e.g. a rolling back of elements such as widows' pensions), are no longer automatically compensated by a partner's income.

We will therefore, in the following, test the implications in terms of country rankings of adding an indicator on low hours, here defined as fewer than 15 hours of work in the reference week. This indicator is inversed. There are several possibilities for adding this indicator to our existing sub-index. A first possibility is to add marginal hours on top of the other four indicators and weight all of the indicators equally (specification 1). A second possibility is to add the component 'marginal hours' to the indicator on excessive hours - in this way one would count only 'normal hours' - that is more than 15 and fewer than 48 hours as representing good job quality outcomes. In this case, both excessive and marginal hours are weighted by $12.5 \%$, the other three original indicators are kept unchanged and weighted by $25 \%$ each (specification 2). A thind more drastic option is to replace the indicator 'my working hours fit with family and social commitments ${ }^{20}$, by the marginal hours indicator (specification 3). A possible justification for this is that this indicator, in contrast to the other three, is subjective in nature and carries the risk of not being independent from institutional circumstances and, for example, gender values. The concept of fitting family and social commitments may privilege countries with social systems (notably child and elderly care) that essentially force workers, particularly women, to choose between full participation in the labour fore and assuming responsibility for child and elderly care. Countries with encompassing systems may score less well on this indicator simply because the need for a 'fit' is not so pronounced.

20. For an in-depth study on this item of the working conditions survey refer to Fagan and Walthery (2011). 
Similarly, men and women may differ in their response behaviour to this indicator as they are likely to perceive the necessity for work-life balance differently - again this will be intermediated by institutional factors and the degree of progressive norms and values existent in a country, which implies that the gender impact will not be constant across countries. ${ }^{21}$ Clearly this is not the intention of an indicator that aims to measure job quality.

All three specifications are tested, with specification 3 being expected to lead to the most pronounced changes in country rankings as it is not unlikely the negative implications of marginal hours notwithstanding - that there will be a correlation between working fewer than 15 hours and agreeing with the statement that 'my working hours fit family and social commitments'.

Table 2 shows the countries' total outcomes for the original specification and the three alternative specifications. Overall, specification 2, where marginal hours are added to the indicator on excessive hours, shows least changes as compared to the original specification, whereas specification 3 , where marginal hours replace the subjective assesment on the fit of working hours with family and social commitments, shows most drastic changes. Interestingly, marked deteriorations are visible in this last specification for countries from all welfare state groups except the central and eastern one which shows marked improvements for five countries. Countries that move up (down) by substantial margins -5 places or more - are marked. An important observation is that both the group of the worst performers and the group of the best performers in the original specifications remain rather stable in the alternative specifications - with the sole exception of the Netherlands which moves from second (original) to ninth (specification 3) place. Overall, the majority of countries does not show drastic changes in the ranking, although low performers tend to improve their index values whereas high performers tend to decline in this regard as the distribution moves closer together and the averages increase. Substantial improvements in the ranking are visible exclusively for a number of central and eastern Europen countries, these being Bulgaria across the alternative specifications, the Baltics and the Czech Republic in specifications 1 and 3 and Poland in specification 2. As regards deteriorations, these are extreme for Germany which was in the upper half of the distribution in the original specification (ranking 10) and in all alternative specifications moves down very close to the bottom (ranking 24, 22 and 26, respectively). The other countries that show marked declines are Austria and the UK (specifications 1 and 3), and additionally, Finland, Ireland and the Netherlands in specifcation 3.

21. Indeed, looking at the raw data, in all Nordic countries the response behaviour of men and women is equal whereas in most other countries women are more likely to respond positively to this variable. 
Table 2 Comparison of ranking and index values between original specification and alternative specifications, totals 2010

\begin{tabular}{|c|c|c|c|c|c|c|c|}
\hline \multicolumn{2}{|c|}{$\begin{array}{l}\text { Original specification } \\
\text { (ranked from lowest to highest) }\end{array}$} & \multicolumn{2}{|l|}{$\begin{array}{l}\text { specification } 1 \\
\text { (5 indicators) }\end{array}$} & \multicolumn{2}{|c|}{$\begin{array}{l}\text { specification } 2 \\
\text { (part of excessive hours) }\end{array}$} & \multicolumn{2}{|c|}{$\begin{array}{l}\text { specification } 3 \\
\text { ('working hours fit' replaced) }\end{array}$} \\
\hline Greece & 0.01 & Greece & 0.16 & Greece & 0.10 & Greece & 0.20 \\
\hline Slovenia & 0.33 & Spain & 0.43 & Slovenia & 0.35 & Germany & 0.40 \\
\hline Spain & 0.38 & Slovenia & 0.44 & Spain & 0.38 & Austria ע & 0.41 \\
\hline Slovakia & 0.39 & Germany ע ע & 0.44 & Italy & 0.41 & Spain & 0.44 \\
\hline Italy & 0.41 & Italy & 0.46 & Slovakia & 0.42 & Slovakia & 0.44 \\
\hline Czech Republic & 0.43 & Austria $\mathbf{y}$ & 0.48 & Germany $\mathbf{y}$ & 0.46 & Slovenia & 0.47 \\
\hline Romania & 0.43 & Slovakia & 0.50 & Malta & 0.47 & Italy & 0.49 \\
\hline Bulgaria & 0.45 & EU15 & 0.51 & Czech Republic & 0.48 & EU15 & 0.49 \\
\hline Malta & 0.46 & EU27 & 0.52 & Romania & 0.48 & Romania & 0.50 \\
\hline Estonia & 0.49 & France & 0.52 & Austria & 0.49 & EU27 & 0.51 \\
\hline France & 0.51 & Czech Rep. $\boldsymbol{\lambda}$ & 0.52 & EU15 & 0.50 & Finland & 0.52 \\
\hline EU27 & 0.52 & Malta & 0.53 & France & 0.51 & UK ע & 0.53 \\
\hline Poland & 0.52 & Romania & 0.55 & EU27 & 0.51 & France & 0.53 \\
\hline Austria & 0.53 & Bulgaria $\pi$ & 0.56 & Bulgaria $\pi$ & 0.51 & Czech Rep. $\boldsymbol{\lambda}$ & 0.53 \\
\hline EU15 & 0.53 & Finland & 0.56 & Finland & 0.52 & Malta & 0.54 \\
\hline Portugal & 0.53 & Estonia & 0.56 & Estonia & 0.52 & Ireland $\boldsymbol{y}$ & 0.54 \\
\hline Latvia & 0.53 & UK ע & 0.58 & Latvia & 0.53 & Poland & 0.55 \\
\hline Cyprus & 0.55 & Poland & 0.58 & Portugal & 0.55 & Estonia $\pi$ & 0.57 \\
\hline Finland & 0.55 & Ireland & 0.58 & Lithuania & 0.57 & Bulgaria $\pi$ & 0.59 \\
\hline Germany & 0.55 & Portugal & 0.59 & Ireland & 0.57 & Portugal & 0.60 \\
\hline Lithuania & 0.57 & Cyprus & 0.59 & Poland $\boldsymbol{\lambda}$ & 0.57 & Cyprus & 0.61 \\
\hline Hungary & 0.59 & Latvia & 0.59 & Cyprus & 0.58 & עetherlands & 0.61 \\
\hline Ireland & 0.61 & Lithuania & 0.65 & Hungary & 0.59 & Latvia $\pi$ & 0.65 \\
\hline UK & 0.62 & Hungary & 0.66 & UK & 0.61 & Luxembourg & 0.70 \\
\hline Luxembourg & 0.69 & Netherlands & 0.67 & Luxembourg & 0.67 & Hungary & 0.70 \\
\hline Belgium & 0.74 & Luxemboug & 0.69 & Netherlands & 0.70 & Lithuania $\pi$ & 0.71 \\
\hline Sweden & 0.76 & Sweden & 0.73 & Sweden & 0.72 & Denmark & 0.73 \\
\hline Netherlands & 0.79 & Belgium & 0.73 & Belgium & 0.74 & Sweden & 0.73 \\
\hline Denmark & 0.84 & Denmark & 0.78 & Denmark & 0.82 & Belgium & 0.75 \\
\hline
\end{tabular}

Own calculations.

Note: countries that change their position by 5 places or more are marked $\boldsymbol{\Xi}$ (downward movement) or $\boldsymbol{\lambda}$ (upward movement).

Both men and women rankings contribute to these overall changes in rankings for a number of countries (not shown). For men, strong upward and downward moves are, however, visible only in specification 3. For women both specification 1 and 3 show rather substantial improvements and declines for a number of countries, whereas specification 2 implies strong changes (declines) for Germany and Austria only. On average, the difference between women and men is reducing visibly in all alternative specifications and particularly in specifications 1 and 3 (Table 3). This was expected as women are on average and in the majority of countries somewhat more likely to state that their working hours fit well with family and social commitments, whereas they are less likely to work regular hours ( $>15$ hours) than men. Particuarly in Germany, the Netherlands and 
Luxembourg, all among the better performers in the original specification, gender differences decline markedly in all alternative specifications but particularly 1 and 3. On the other hand, gender gaps are reduced but remain substantial across the alternative specifications and particularly in specification 2 in three countries at the top of the distribution in the original specification, namely Denmark, Belgium and the UK; these countries belonged to the group with the highest gender differences in the original specification (Table 4). Overall, all alternative specifications lead to a narrower distribution of countries than the original one.

\section{New indicators available for the sub-index on working conditions and job security and collective interest representation}

An important question is how to deal with new and relevant data that becomes available. If we want to ensure comparability over time we cannot take account of it, and yet in some instances it can be useful to recalculate a sub-index based on the new more pertinent data for the latest year of the index.

In order to take account of sectoral developments, in particular the rise of the services sector, the working conditions and job security sub-index that currently contains items that capture physical work factors, work autonomy and work intensity could becomplemented by psycho-social risk factors that capture the response of workers to their work content and work environment including customers, colleagues and bosses. While items capturing psycho-social factors were, for the most part, not available in 2005, several useful items that would potentially allow construction of an indicator on psycho-social risk that could complement the other four indicators in this sub-index are now available in the 2010 EWCS data. ${ }^{22}$ One could, moreover, consider including the topic of 'violence and harassment at work'; information on physical violence, bullying/ harassment and sexual harassment is available in the 2005 and 2010 data, but is not entirely consistent over time.

Our original index on collective interest representation is rather poor in that it is based only on trade union density and collective bargaining coverage (both not gendered) and thus does not takeaccount of direct participation of workers at the workplace (such as the German works councils). To take account of this to some degree, originally we had also included a question from the EWCS data which captured workers' involvement in decisions on work organisation. However, this question is no longer available in the EWCS 2010 data. On the other hand, a number of new relevant items on the role of workers' representatives and the direct involvement of workers at the firm level are now available and could potentially be used to recalculate the 2010 sub-index on collective interest representation. Respondents are now being asked if there is an employee

22. These items are as follows: "Does your job involve handling angry clients?", "Do you know what is expected of you at work?", "Does your job involve tasks that are in conflict with your personal values ?", "Does your job require that you hide your feelings ?", "If you make mistakes at work, could it cause physical injuries to people?", "If you make mistakes at work could it cause financial loss of the company" (Eurofound 2010). 
representative at their workplace and if they have raised work-related problems with this employee representative in the previous year. Moreover, they are being asked if management holds meetings in which they can express their views about what is happening in the organisation. A tabulation of these three items from the EWCS 2010 data does, however, reveal that the use of these indicators would not improve the position of e.g. Germany in the J QI sub-index on collective interest representation substantially, as might have been expected. Indeed, as in our subindex (Figure 7), it is performing below the EU27 average on all three items, while the Nordic countries and to a lesser degree Belgium are outperforming the other countries, which is in line with their top-ranking according to our subindex. In short the results would not be affected in any major way.

Thefact that the original item on worker involvement has been dropped from the survey in order to add a more coherent set of questions on workers' participation in the latest survey is illustrative of the problems that can arise when building indicators that are supposed to bestableover time. In addition to the new EWCS questions on workers' participation and representation, the ICTWSS data base which we used to assemble our indicators on trade union density and collective bargaining coverage, now has gendered information available on trade union membership. This was not the case in 2008 when we used a preliminary version of this data base. However, as the data is incomplete with gendered information missing for a number of countries and the data where available refer to different years, it is not (yet) possible to recalculate this index in a gendered version. A comparison of the trade union membership figures for men and women, where available, highlights, however, that in the majority of countries men are more likely than women to be trade union members.

\section{Conclusions}

This paper presents the results of our updating of the ETUI J ob Quality Index for the EU27 countries, based on 2010 data. A wide range of detailed findings have been described. Beyond the detail, the following key messages emerge.

In terms of the substance of our results:

- The crisis seems to have affected different dimensions of job quality in different ways. Overall, we see a decline in measured job quality, even if it is rather small. More interestingly - also in view of the fact that a different outcome would emerge if we weighted the six components differently - we see quite substantial changes in four of the six components. But they go in different directions. The wages component declines appreciably. Even stronger is the increase in the use of parttime and fixed-term contracts and/or in the extent to which workers reported that they were working in such jobs involuntarily. Moreover, the numbers of workers who are afraid to lose their job have increased markedly. These are clear signs of the bargaining-power effect. On the 
other hand, job quality has risen to the extent that excessive hours have been reduced and various measures of work intensity have improved. Also work autonomy seems to have improved. It seems likely that this is because jobs with little autonomy (e.g. in construction) have been disproportionately shed (composition effect).

- J ob quality levels in Europe remain highly diverse. The very substantial range across countries (from around 0.3 to 0.8 on our zero-to-one scale) in overall job quality has not changed in any major way, despite the fact that the worst performer in 2005, Poland, has seen the largest improvement. The groups of countries with significant improvements and deteriorations are quite diverse. Thus these changes have not led to a major shift in the position of country groups (such as the Nordic, Anglo-Saxon or 'southern' groups) in the distribution.

- There is a link between the severity of the crisis and overall job quality developments, but it is not particularly strong. There is a positive relationship between the change in the unemployment rate between 2005 and 2010 - note that this covers also the pre-crisis period which in some countries was one of economic boom - with the change in the overall J QI over the same period, most clearly illustrated by the two extreme cases, Poland and Ireland. The relationship is not particularly strong, however, and there are several exceptions. It is with respect to the incidence of involuntary part-time and fixed-term work that the crisis link is most clear-cut.

In terms of procedure and methodology:

- Overall, this update of the ETUI's JQI appears to confirm the feasibility and desirability of attempting to assess the multi-dimensional phenomenon that is job quality by means of a composite index that can be periodically updated. The results seem on the whole plausible and not unduly affected by inexplicable shifts that might, for instance, reflect changes in the methodology of the underlying surveys. The results can be discussed and interpreted both at a highly aggregated level and in a more detailed way with respect to specific indicators.

- At the same time, as we have repeatedly emphasised also in previous work, the limitations of such a composite index need to be borne in mind. The alternative specifications analysed in Section 5 did not lead to a major reassessment of the broad ranking of European countries in terms of job quality. Some changes in the specification did, however, lead to substantial changes for certain countries and in specific subindices. It is important to remember that all the indicators used involve trade-offs. Broadly we remain convinced that the JQI reflects reasonable choices given the data limitations we face. What is clearly key is to provide the maximum transparency regarding the choices made. 


\section{Bibliography}

Berckmans, P., Bourdeaud'hui, R. and Vanderhaeghe, S. (2011) The Flemish workabilitymonitor: abroad focus on quality of work, WISO, 34 (Sonderheft), $16 f f$.

Bothfeld, S. and Leschke, J . (2012) 'More and better jobs': is quality of work still an issue - and was it ever?, Transfer, 18 (3), 337-353.

Dahl, S-A., Nesheim, T. Olsen, K.M. (2009) Quality of work: concept and measurement, in A. Guillén and S. Dahl (eds) Quality of work in the European Union: concept, data and debates form a transnational perspective, Brussels: PIE- Peter Lang, 19-40.

Davoine, L., Erhel, C. and Guergoat-Lariviere, M. (2008) Monitoring quality in work: European Employment Strategy indicators and beyond, International Labour Review, 147 (2-3), 163-198.

Drobnic, S. and Guillén, A. (eds) (2011) Work-life balance in Europe: the roleof job quality, New York: Palgrave Macmillan.

Esping-Andersen, G. (1990) Thethreeworlds of welfarecapitalism, Cambridge: Polity Press.

Esping-Andersen, G. (1999) Social foundations in postindustrial economies. Oxford: Oxford University Press.

Eurofound (2010) Questionnaire for Fifth European Survey in Working Conditions (2010), Dublin. http:/ / www.eurofound.europa.eu/ surveys/ ewcs/ 2010/ documents/masterquestionnaire.pdf

Fagan, C. and Walthery, P. (2011) J ob quality and the perceived work-life balance fit between work hours and personal commitments: a comparison of parents and older workers in Europe, in S. Drobnic and A. Guillén (eds.) Work-life balance in Europe: the role of job quality, New York: Palgrave Macmillan, 69-94.

Fagan, C. (2004) Gender and working time in industrialised countries, in J . C. Messenger (ed.) Working time and workers' preference in industrialised countries: finding the balance, Abindgdon: Routledge, 108-146.

Ferrera, M. (1996) The 'Southern model' of welfare in social Europe, J ournal of European Social Policy, 6 (1),17-37.

Fuchs, T. (2009) Der DGB-Index Gute Arbeit, in E. Kistler and F. Mußmann (eds) Arbeitsgestaltung als Zukunftsaufgabe. Die Qualität der Arbeit, Hamburg: VSA, 187-222.

Gallie, D. (ed.) (2007) Employment regimes and the quality of work, Oxford: Oxford University Press.

Green, F. (2006) Demanding work: the paradox of job quality in the affluent economy, Princeton: Princeton University Press.

Hofinger, C., Kien, C., Michenthaler, G. and Raml, R. (2009) Zwölf Jahre österreichischer Arbeitsklimaindex - Erkenntnisse und Ausblick, in E. Kistler and F. Mußmann (eds) Arbeitsgestaltung als Zukunftsaufgabe. Die Qualität der Arbeit, Hamburg: VSA, 122-142. 
Keune, M. (2010) Welfare states in Central and Eastern Europe in comparative perspective: types and performance, in C. Klenner and S. Leiber (2010) Welfare states and gender equality in Central and Eastern Europe. Continuity and post-socialist transformation in the EU Member States, Brussels: ETUI, 57-80.

Leschke, J., Peña-Casas, R. and Watt, A. (2011) Possibilities and challenges for building a European indicator on job quality, in J. Busch, M. Flore, H. Kohl and H. Schlatermund (eds) Socially unbalanced Europe: socio-political proposal in times of crisis, Pontypool: Merlin Press, 268-288.

Leschke, J., Watt, A. and Finn, M. (2008) Putting a number on job quality? Constructing a European J ob Quality Index, Working Paper 2008.03, Brussels: ETUI. http:// www.etui.org/ Publications2/Working-Papers/Puttinga-number-on-job-quality

Leschke, J . and Watt, A. (2008) J ob quality in Europe, Working Paper 2008.07, Brussels: ETUI. http:// www.etui.org/ Publications2/Working-Papers/J obquality-in-Europe

Leschke, J . and Watt, A. (2010) How do institutions affect the labour market adjustment to the economic crisis in different EU countries?, WorkingPaper 2010.04, Brussels: ETUI. http:// www.etui.org/ Publications2/Working-Papers/ How-do-institutions-affect-the-labour-market-adjustment-to-the-economiccrisis-in-different-EU-countries/

OECD (2008) Handbook on constructing composite indicators: methodology and user guide, Paris: OECD.

Peña-Casas, R. (2009) More and better jobs: conceptual framework and monitoring indicators of quality of work and employment in theEU Policy Arena, REC-WP Working Papers on the Reconciliation of Work and Welfare in Europe 06-2009.

\section{Data sources}

European Working Conditions Survey 2005 and 2010, user data base and special extracts, Dublin: Eurofound.

EU-SILC user database (2010 version), Luxembourg: Eurostat. EU Labour Force Survey, online database, Luxembourg: Eurostat: AMECO database, Brussels: European Commission. 



\section{Annex 1}

Table 1 Sub-indices and their indicators* in the Job Quality Index: 2005 and 2010

\begin{tabular}{|c|c|c|c|}
\hline Sub-indices & Indicators & Data source & Weighting \\
\hline Wages & $\begin{array}{l}\text { Nominal compensation per employee in PPS deflated using CPI; gender } \\
\text { figures estimated using gender pay gap } \\
\text { In-work poverty (those individuals who are classified as employed whose } \\
\text { household equivalised disposable income is below } 60 \% \text { of the national } \\
\text { median equivalised income) }\end{array}$ & $\begin{array}{l}\text { AMECO/ Eurostat } \\
\text { Eurostat }\end{array}$ & 30 \\
\hline $\begin{array}{l}\text { Non-standard } \\
\text { forms of } \\
\text { employment }\end{array}$ & $\begin{array}{l}\text { Temporary employment }{ }^{(a)} \text { as share of total number of employees*share of } \\
\text { temps indicating that main reason was that they could not find permanent } \\
\text { job } \\
\text { Part-time employment as share of total number of employees* share of } \\
\text { part-timers indicating that main reason was that they could not find full- } \\
\text { time job }\end{array}$ & $\begin{array}{l}\text { Eurostat, LFS } \\
\text { Eurostat, LFS }\end{array}$ & 50 \\
\hline $\begin{array}{l}\text { Working time } \\
\text { and work-life } \\
\text { balance }\end{array}$ & $\begin{array}{l}\text { Share of employees working more than } 48 \text { hours a week } \\
\text { Average of share of workers on shift work; Saturday work; Sunday work; } \\
\text { night work; evening work } \\
\text { Voluntary part-time work (share of people working less than } 30 \text { hours who } \\
\text { state as reason that they do not want to work more hours) } \\
\text { "Working hours fit in with family/social commitment" }\end{array}$ & $\begin{array}{l}\text { Eurostat, LFS, } \\
\text { customized tables } \\
\text { Eurostat, LFS } \\
\text { EU-SILC } \\
\text { EWCS }\end{array}$ & $\begin{array}{l}25 \\
25 \\
25\end{array}$ \\
\hline $\begin{array}{l}\text { Working } \\
\text { conditions and } \\
\text { job security }\end{array}$ & $\begin{array}{l}\text { 'Work intensity' (working at a very high speed, working to tight deadlines } \\
\text { and not having enough time to get the job done) } \\
\text { 'Work autonomy' (can choose/change order of tasks, methods of work, } \\
\text { speed of work, can take a break when you wish) } \\
\text { 'Physical work factors' (vibrations, noise, high/low temperature, breathing } \\
\text { in smoke, fumes, powder, dust, vapours such as solvents and thinners, } \\
\text { handling chemical substances, radiation (b), tobacco smoke from other } \\
\text { people, infectious materials, tiring or painful positions, lifting or moving } \\
\text { people, carrying or moving heavy loads, standing or walking, repetitive } \\
\text { hand or arm movements) } \\
\text { "I might lose my job in the next six months" }\end{array}$ & $\begin{array}{l}\text { EWCS } \\
\text { EWCS } \\
\text { EWCS } \\
\text { EWCS }\end{array}$ & $\begin{array}{l}25 \\
25 \\
25\end{array}$ \\
\hline $\begin{array}{l}\text { Skills and } \\
\text { career } \\
\text { development }\end{array}$ & $\begin{array}{l}\text { Share of population ( } 25-64 \text { years) participating in education/training over } \\
\text { four weeks prior to survey } \\
\text { 'My job offers good prospects for career advancement' }\end{array}$ & $\begin{array}{l}\text { Eurostat, LFS } \\
\text { EWCS }\end{array}$ & 60 \\
\hline $\begin{array}{l}\text { Collective } \\
\text { interest } \\
\text { representation }\end{array}$ & $\begin{array}{l}\text { Collective bargaining coverage } \\
\text { Trade union density } \\
\text { Consulted about changes in work organisation }{ }^{(\mathrm{d})}\end{array}$ & $\begin{array}{l}\text { ICTWSS database }{ }^{(c)} \\
\text { ICTWSS } \\
\text { Database } \\
\text { EWCS }\end{array}$ & $\begin{array}{l}40(2005) \\
60(2010) \\
30(2005) \\
40(2010) \\
30(2005)-(2010)\end{array}$ \\
\hline
\end{tabular}

Note: Information on response categories and the coding of variables can be found in Leschke et al. 2008:. $18 \mathrm{f}$.

a The LFS data on temporary employment refers to all contracts of fixed duration. This encompasses also temporary agency work as long as there is no permanent contract with the agency.

b included in 2005, no longer available in 2010 data.

c for 2005 supplemented by national reports/expert opinions.

d included in 2005, no longer available in 2010 data, for time comparison the 2005 sub-index has been recalculated without this indicator. 


\section{Annex 2}

\section{Country-specific radar charts for ranking on job quality sub-indices}

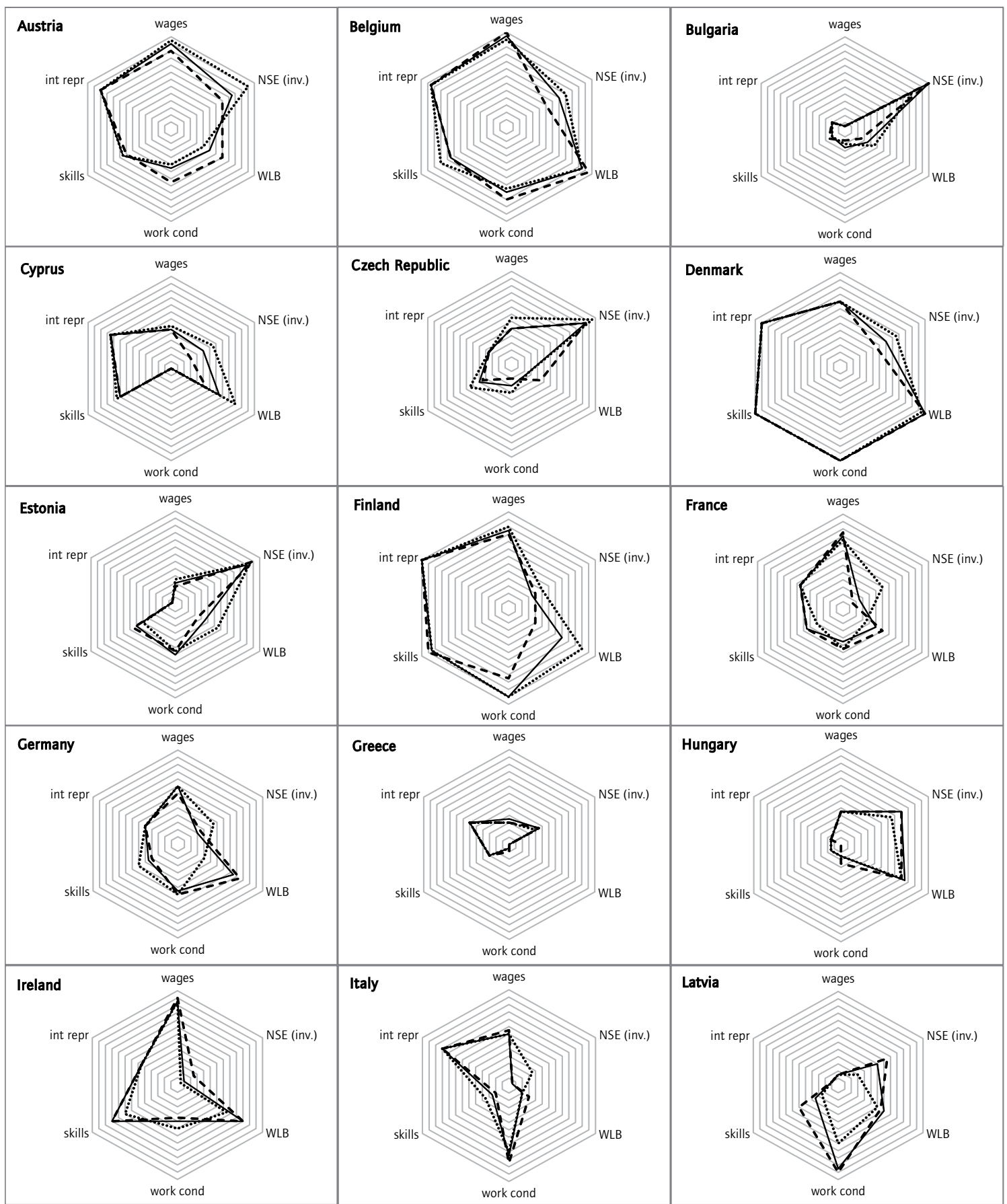

_ total ...... men _ - women WLB: Working time and work-life balance NSE: non-standard employment 


\section{Country-specific radar charts for ranking on job quality sub-indices}

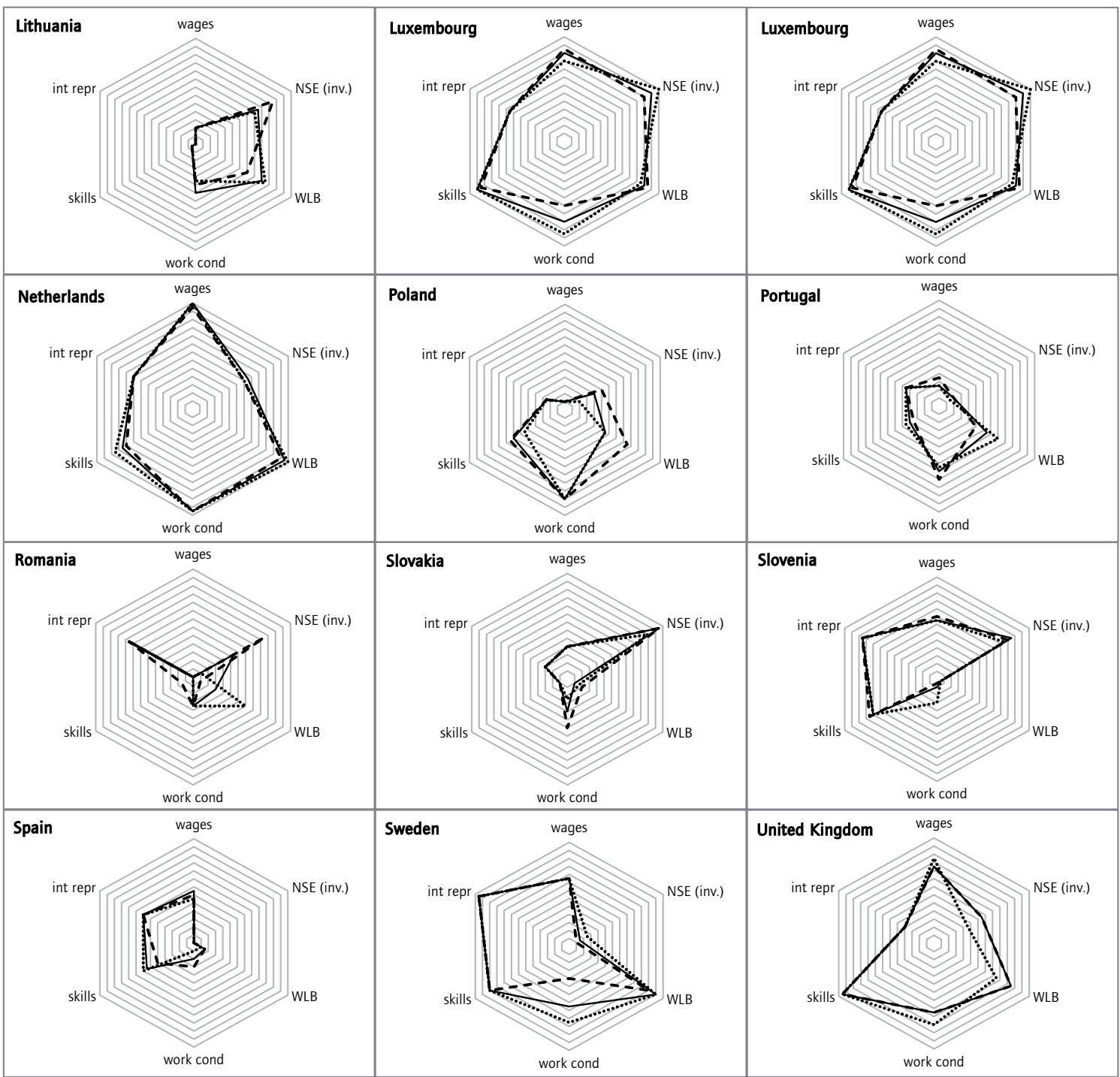

— total ...... men _ _- women WLB: Working time and work-life balance NSE: non-standard employment 


\section{Annex 3}

Table 3a Absolute changes between 2005 and 2010 in sub-indices and overall JQI (sorted by country)

\begin{tabular}{|c|c|c|c|c|c|c|c|}
\hline & wages & $\begin{array}{l}\text { involuntary } \\
\text { non-standard } \\
\text { (inverted) }\end{array}$ & $\begin{array}{c}\text { working time } \\
\text { and WLB }\end{array}$ & $\begin{array}{l}\text { working condi- } \\
\text { tions and job } \\
\text { security }\end{array}$ & $\begin{array}{c}\text { skills and } \\
\text { career } \\
\text { development }\end{array}$ & $\begin{array}{l}\text { collective } \\
\text { interest rep- } \\
\text { resentation }\end{array}$ & $\begin{array}{l}\text { total JQI - } \\
\text { adjusted }\end{array}$ \\
\hline Austria & 0.03 & -0.01 & 0.02 & 0.02 & -0.10 & -0.03 & -0.01 \\
\hline Belgium & -0.04 & 0.07 & 0.10 & -0.05 & 0.11 & 0.00 & 0.04 \\
\hline Bulgaria & 0.00 & 0.01 & 0.12 & -0.02 & 0.05 & -0.06 & 0.02 \\
\hline Cyprus & 0.01 & -0.04 & -0.02 & -0.06 & 0.13 & -0.07 & 0.00 \\
\hline Czech Republic & -0.01 & -0.02 & 0.04 & 0.18 & 0.09 & -0.07 & 0.04 \\
\hline Denmark & -0.02 & -0.03 & 0.11 & 0.11 & 0.08 & 0.00 & 0.04 \\
\hline Estonia & 0.02 & -0.07 & -0.02 & -0.03 & 0.12 & -0.12 & -0.01 \\
\hline EU15 & -0.04 & -0.08 & 0.00 & 0.00 & -0.04 & -0.02 & -0.03 \\
\hline EU27 & -0.04 & -0.06 & 0.04 & 0.02 & -0.01 & -0.02 & -0.01 \\
\hline Finland & 0.03 & 0.03 & 0.05 & 0.13 & -0.05 & -0.01 & 0.02 \\
\hline France & -0.04 & 0.00 & -0.08 & -0.14 & -0.12 & -0.04 & -0.08 \\
\hline Germany & -0.19 & 0.02 & -0.04 & 0.15 & -0.04 & -0.02 & -0.02 \\
\hline Greece & -0.07 & -0.11 & -0.02 & 0.06 & 0.06 & -0.02 & 0.00 \\
\hline Hungary & 0.01 & -0.13 & 0.13 & 0.01 & 0.04 & -0.02 & 0.01 \\
\hline Ireland & 0.06 & -0.55 & 0.09 & -0.29 & 0.03 & -0.07 & -0.11 \\
\hline Italy & 0.01 & -0.23 & 0.05 & -0.05 & 0.02 & 0.00 & -0.02 \\
\hline Latvia & 0.04 & -0.16 & 0.21 & 0.00 & -0.01 & 0.02 & 0.01 \\
\hline Lithuania & 0.01 & 0.07 & 0.05 & 0.02 & -0.10 & -0.04 & -0.01 \\
\hline Luxembourg & -0.05 & 0.02 & 0.07 & -0.14 & 0.22 & -0.05 & 0.02 \\
\hline Malta & 0.00 & -0.02 & 0.08 & 0.06 & 0.09 & -0.03 & 0.03 \\
\hline Netherlands & -0.04 & 0.01 & 0.10 & 0.05 & -0.03 & -0.03 & 0.00 \\
\hline Poland & 0.06 & 0.10 & 0.27 & 0.17 & 0.18 & 0.01 & 0.13 \\
\hline Portugal & -0.01 & -0.12 & 0.03 & 0.17 & -0.04 & -0.13 & -0.03 \\
\hline Romania & -0.31 & -0.03 & 0.30 & 0.06 & 0.03 & 0.02 & 0.02 \\
\hline Slovakia & 0.05 & -0.07 & 0.15 & 0.02 & 0.00 & -0.14 & 0.01 \\
\hline Slovenia & -0.04 & -0.03 & 0.05 & 0.06 & 0.04 & -0.07 & 0.01 \\
\hline Spain & 0.01 & -0.11 & 0.00 & 0.04 & 0.01 & 0.02 & -0.01 \\
\hline Sweden & 0.02 & -0.06 & 0.07 & -0.09 & -0.11 & -0.05 & -0.05 \\
\hline United Kingdom & 0.03 & -0.19 & -0.01 & -0.07 & -0.08 & -0.01 & -0.06 \\
\hline
\end{tabular}


Table 3b Absolute changes between 2005 and 2010 in sub-indices and overall JQI (sorted by size of change)

\begin{tabular}{|c|c|c|c|c|c|c|c|c|c|c|c|c|c|}
\hline \multicolumn{2}{|l|}{ Wages } & \multicolumn{2}{|c|}{$\begin{array}{l}\text { Involuntary } \\
\text { non-standard } \\
\text { (inverted) }\end{array}$} & \multicolumn{2}{|c|}{$\begin{array}{l}\text { working time } \\
\text { and WLB }\end{array}$} & \multicolumn{2}{|c|}{$\begin{array}{l}\text { working } \\
\text { conditions and } \\
\text { job security }\end{array}$} & \multicolumn{2}{|c|}{$\begin{array}{c}\text { skills and career } \\
\text { development }\end{array}$} & \multicolumn{2}{|c|}{$\begin{array}{c}\text { collective } \\
\text { interest } \\
\text { representation }\end{array}$} & \multicolumn{2}{|c|}{$\begin{array}{l}\text { total JQI - } \\
\text { adjusted }\end{array}$} \\
\hline RO & -0.31 & IE & -0.55 & FR & -0.08 & IE & -0.29 & FR & -0.12 & SK & -0.14 & IE & -0.11 \\
\hline $\mathrm{DE}$ & -0.19 & IT & -0.23 & $\mathrm{DE}$ & -0.04 & LU & -0.14 & SE & -0.11 & PT & -0.13 & FR & -0.08 \\
\hline GR & -0.07 & UK & -0.19 & GR & -0.02 & FR & -0.14 & AT & -0.10 & $\mathrm{EE}$ & -0.12 & UK & -0.06 \\
\hline LU & -0.05 & LV & -0.16 & $\mathrm{CY}$ & -0.02 & SE & -0.09 & LT & -0.10 & SI & -0.07 & SE & -0.05 \\
\hline $\mathrm{BE}$ & -0.04 & $\mathrm{HU}$ & -0.13 & $\mathrm{EE}$ & -0.02 & UK & -0.07 & UK & -0.08 & $\mathrm{CY}$ & -0.07 & EU15 & -0.03 \\
\hline EU27 & -0.04 & PT & -0.12 & UK & -0.01 & $\mathrm{CY}$ & -0.06 & $\mathrm{FI}$ & -0.05 & IE & -0.07 & PT & -0.03 \\
\hline EU15 & -0.04 & ES & -0.11 & EU15 & 0.00 & BE & -0.05 & PT & -0.04 & $C Z$ & -0.07 & $\mathrm{DE}$ & -0.02 \\
\hline FR & -0.04 & GR & -0.11 & ES & 0.00 & IT & -0.05 & $\mathrm{DE}$ & -0.04 & BG & -0.06 & IT & -0.02 \\
\hline NL & -0.04 & EU15 & -0.08 & AT & 0.02 & $\mathrm{EE}$ & -0.03 & EU15 & -0.04 & LU & -0.05 & LT & -0.01 \\
\hline SI & -0.04 & SK & -0.07 & PT & 0.03 & BG & -0.02 & NL & -0.03 & SE & -0.05 & EU27 & -0.01 \\
\hline DK & -0.02 & $\mathrm{EE}$ & -0.07 & $\mathrm{CZ}$ & 0.04 & EU15 & 0.00 & EU27 & -0.01 & LT & -0.04 & AT & -0.01 \\
\hline$C Z$ & -0.01 & SE & -0.06 & EU27 & 0.04 & LV & 0.00 & LV & -0.01 & FR & -0.04 & EE & -0.01 \\
\hline PT & -0.01 & EU27 & -0.06 & SI & 0.05 & HU & 0.01 & SK & 0.00 & MT & -0.03 & ES & -0.01 \\
\hline MT & 0.00 & $\mathrm{CY}$ & -0.04 & $\mathrm{FI}$ & 0.05 & LT & 0.02 & ES & 0.01 & $\mathrm{NL}$ & -0.03 & $\mathrm{CY}$ & 0.00 \\
\hline BC & 0.00 & DK & -0.03 & IT & 0.05 & SK & 0.02 & IT & 0.02 & AT & -0.03 & GR & 0.00 \\
\hline ES & 0.01 & RO & -0.03 & LT & 0.05 & EU27 & 0.02 & IE & 0.03 & GR & -0.02 & NL & 0.00 \\
\hline $\mathrm{CY}$ & 0.01 & SI & -0.03 & LU & 0.07 & AT & 0.02 & RO & 0.03 & $\mathrm{DE}$ & -0.02 & SK & 0.01 \\
\hline IT & 0.01 & MT & -0.02 & SE & 0.07 & ES & 0.04 & SI & 0.04 & $\mathrm{HU}$ & -0.02 & SI & 0.01 \\
\hline LT & 0.01 & $C Z$ & -0.02 & MT & 0.08 & NL & 0.05 & $\mathrm{HU}$ & 0.04 & EU15 & -0.02 & HU & 0.01 \\
\hline HU & 0.01 & AT & -0.01 & IE & 0.09 & GR & 0.06 & BG & 0.05 & EU27 & -0.02 & LV & 0.01 \\
\hline SE & 0.02 & FR & 0.00 & NL & 0.10 & SI & 0.06 & GR & 0.06 & FI & -0.01 & RO & 0.02 \\
\hline $\mathrm{EE}$ & 0.02 & NL & 0.01 & BE & 0.10 & MT & 0.06 & DK & 0.08 & UK & -0.01 & BG & 0.02 \\
\hline FI & 0.03 & BG & 0.01 & DK & 0.11 & RO & 0.06 & MT & 0.09 & DK & 0.00 & LU & 0.02 \\
\hline AT & 0.03 & $\mathrm{DE}$ & 0.02 & BG & 0.12 & DK & 0.11 & $C Z$ & 0.09 & IT & 0.00 & FI & 0.02 \\
\hline UK & 0.03 & LU & 0.02 & HU & 0.13 & $\mathrm{FI}$ & 0.13 & $\mathrm{BE}$ & 0.11 & $\mathrm{BE}$ & 0.00 & MT & 0.03 \\
\hline LV & 0.04 & $\mathrm{FI}$ & 0.03 & SK & 0.15 & $\mathrm{DE}$ & 0.15 & $\mathrm{EE}$ & 0.12 & PL & 0.01 & DK & 0.04 \\
\hline SK & 0.05 & LT & 0.07 & LV & 0.21 & PL & 0.17 & $\mathrm{CY}$ & 0.13 & RO & 0.02 & $\mathrm{BE}$ & 0.04 \\
\hline PL & 0.06 & $\mathrm{BE}$ & 0.07 & PL & 0.27 & PT & 0.17 & PL & 0.18 & LV & 0.02 & $C Z$ & 0.04 \\
\hline IE & 0.06 & PL & 0.10 & RO & 0.30 & $C Z$ & 0.18 & LU & 0.22 & ES & 0.02 & PL & 0.13 \\
\hline
\end{tabular}




\section{ETUI Working Papers}

Magdalena Bernaciak

Social dumping: political catchphrase or threat to labour standards?

WP 2012.06

Ive Marx, Sarah Marchal and Brian Nolan

Mind the gap: net incomes of minimum wage workers in the EU and the United States

WP 2012.05

Isabelle Schömann and Stefan Clauwaert

The crisis and national labour law reforms: a mapping exercise WP 2012.04 - DE, EN, ES, FR, IT

Maarten Keune and Colin Crouch

The governance of economic uncertainty: beyond the 'new social risks' analysis

WP 2012.03

Janine Leschke

Has the economic crisis contributed to more segmentation in labour market and welfare outcomes?

WP 2012.02

Paul de Beer

The impact of the crisis on earnings and income distribution in the EU

WP 2012.01

Norman Wagner

Financing social security - business as usual?

WP 2011.09

Aline Conchon

Employee representation in corporate governance: part of the economic or the social sphere?

WP 2011.08

David Natali

Pensions after the financial and economic crisis: a comparative analysis of recent reforms in Europe

WP 2011.07

Kurt Vandaele

Sustaining or abandoning 'social peace'? Strike developments and trends in Europe since the 1990s

WP 2011.05 
J anine Leschke and Maria J epsen

The economic crisis - challenge or opportunity for gender equality in social policy outcomes?

A comparison of Denmark, Germany and the UK

WP 2011.04

Vera Glassner and Philippe Pochet

Why trade unions seek to coordinate wages and collective bargaining in the Eurozone: past developments and future prospects

WP 2011.03

Sotiria Theodoropoulou and Andrew Watt

Withdrawal symptoms: an assessment of the austerity packages in Europe

WP 2011.02

J ean-Claude Barbier

Changes in political discourse from the Lisbon Strategy to Europe 2020: tracing the fate of 'social policy'?

WP 2011.01

Vera Glassner

The public sector in the crisis

WP 2010.07

Andranik S. Tangian

Not for bad weather: macroanalysis of flexicurity with regard to the crisis

WP 2010.06

Aída María Ponce Del Castillo

The EU approach to regulating nanotechnology

WP 2010.05

J anine Leschke and Andrew Watt

How do institutions affect the labour market adjustment to the economic crisis in different EU countries?

WP 2010.04

Rory O'Farrell

Wages in the crisis

WP 2010.03

These publications can be downloaded free of charge from our website. Please visit: http:/ / www.etui.org/ publications 
European

Trade Union Institute

Bd du Roi Albert II, 5

1210 Brussels

Belgium

Tel.: +32 (0)2 2240470

Fax: +32 (0)2 2240502

etui@etui.org

www.etui.org 